\title{
EI VIH y las ramificaciones para la seguridad alimentaria y la salud infantil en comunidades afectadas
}

\author{
Noel W. Solomons ${ }^{a} \quad$ Gwen Ellen O'Donnell ${ }^{b}$ \\ a Centro de Estudios en Sensoriopatías, Senectud e Impedimentos y Alteraciones Metabólicas -CeSSIAM-, \\ Guatemala City, Guatemala; ${ }^{b}$ Project Concern International, Washington D.C., EE.UU.
}

\begin{abstract}
Palabras clave
Virus de la inmunodeficiencia humana · Síndrome de inmunodeficiencia adquirida • Inseguridad alimentaria • Seguridad alimentaria - Países en vías de desarrollo • Agricultura • Asistencia alimentaria • Infecciones oportunistas $\cdot$ Pobreza
\end{abstract}

\section{Extracto}

Los primeros casos de síndrome de inmunodeficiencia adquirida (SIDA), causada por el virus de la inmunodeficiencia humana $(\mathrm{VIH})$, se identificaron en 1981. Actualmente se estima en $39 \mathrm{mi}-$ llones las personas infectadas en todo el mundo por el virus. Aunque el $64 \%$ de estos individuos viven actualmente en la pobreza de África subsahariana, la pandemia se está propagando en estos momentos con máxima rapidez por las naciones más grandes de Asia. Se dice que existe un estado de seguridad alimentaria cuando toda la población, en todo momento, tiene acceso a comida suficiente, segura y nutritiva para satisfacer sus necesidades dietéticas y preferencias alimentarias, con miras a una vida activa y sana. En la pandemia de VIH/SIDA se suscita una preocupación con respecto a la inseguridad alimentaria, basada en los principios bien conocidos de la interacción entre malnutrición e infección; los individuos con más deficiencias nutricionales son afectados más severamente por patógenos infecciosos, al tiempo que los estragos causados por la infección tienden a agotar las reservas nutricionales. Las consecuencias sociales y clínicas del VIH/SIDA ponen en peligro el acceso a los alimentos en zonas ya castigadas por la pobreza y el deterioro ambiental. Las intervenciones relacionadas con la produc- tividad agrícola, la generación de ingresos y la asistencia alimentaria deben ser cada una trabajada con pericia y adaptada dentro del contexto comunitario local, y reconocidas como necesarias para mitigar los efectos adversos del VIH/SIDA en la seguridad alimentaria. UNICEF ha establecido que la asistencia - definida como la provisión de tiempo, atención y apoyo en el hogar y en la comunidad para satisfacer las necesidades físicas, mentales y sociales del niño en fase de crecimiento y otros miembros del ámbito doméstico - como uno de los componentes de sus esfuerzos para fomentar la supervivencia infantil. En su dominio destacan el cuidado de las mujeres, las prácticas de amamantamiento y alimentación infantil, la atención psicosocial, la preparación de los alimentos, las prácticas higiénicas y de salud domestica. En el contexto de niños VIH positivos, se está aplicando actualmente el enfoque de desviación positiva, que consiste en identificar las conductas de cuidados domésticos que han generado en niños los mejores resultados en cuanto al crecimiento, la salud y el desarrollo. El estigma es un factor dominante que tiende a aislar los hogares afectados con miembros VIH positivos y que complica el contexto social en el que pueden realizarse intervenciones de seguridad alimentaria y de asistencia. Se han identificado lagunas en nuestros conocimientos sobre las relaciones entre seguridad alimentaria y VIH/SIDA. Entre las interrogantes que abarca la investigación destacan la eficacia real de la asistencia alimentaria para mitigar los efectos del VIH y la interacción entre el estado de seguridad alimentaria y la eficacia y seguridad de la terapia antirretroviral. No obstante, la investigación es en cierto modo un lujo dentro de la adjudicación de escasos recursos financieros, dando mayor importancia a la recogida y la codifi-

\section{KARGER}

Fax +4161306 1234

E-Mail karger@karger.ch

www.karger.com (c) 2007 Nestec Ltd., Vevey/S. Karger AG, Basel

0252-8185/07/0651-0009\$23.50/0

Accesible online en:

www.karger.com/ans
Noel W. Solomons

CeSSIAM in Guatemala

PO Box 02-5339, Section 6163/Guatemala

Miami, FL 33102-5339 (USA)

Tel./Fax +502 2473 3942, E-Mail cessiam@guate.net.gt 
cación de experiencia pragmática útil para intervenciones mitigantes desde la valiosa experiencia que está siendo recolectado actualmente sobre el terreno por los trabajadores de campo y las propias comunidades.

Copyright $\odot 2007$ Nestec Ltd., Vevey/S. Karger AG, Basel

\section{Introducción e historia contextual de la pandemia de SIDA}

El 5 de junio de 1981 se describió el primer informe de casos clínicos de una enfermedad consuntiva asociada a mortalidad, causada por infecciones, a la que se dio posteriormente el nombre de Síndrome de Inmunodeficiencia Adquirida o SIDA, en hombres homosexuales de Los Ángeles, CA [1]. La enfermedad es transmitida por el Virus de la Inmunodeficiencia Humana (VIH). Actualmente se estima que la primera transmisión del virus de una especie de simios al humano pudo haber ocurrido 20 a 40 años antes, dando lugar a un reservorio estrechamente circunscrito a África [2]. La identificación subsiguiente del SIDA en el Caribe, Brasil y África subsahariana alertó de una epidemia a la comunidad de salud pública mundial [3].

La humanidad ha experimentado epidemias a lo largo de toda su historia. La peste bubónica (muerte negra) diezmó hasta $1 / 3$ de la población europea durante varias reapariciones desde el siglo XI hasta el siglo XV. Epidemias letales de cólera atormentaron también a Europa antes de la época de John Snow, a mediados del siglo XIX [4]. El cólera sigue siendo holoendémico en partes del sur de Asia hasta la fecha [5]. La viruela constituyó una pandemia mundial desde la antigüedad hasta su erradicación en 1979 [6]. También aparecieron pandemias episódicas de influenza, siendo el ejemplo más devastador el que se vivió en 1918 y 1919, a finales de la Primera Guerra Mundial; se estima que en la Gran Epidemia Gripal sucumbieron en todo el mundo alrededor de 3 millones de personas.

La movilidad de las poblaciones es uno de los factores cruciales en la transmisión de enfermedades de persona a persona. Al respecto, es probable que el SIDA sea la primera epidemia de la época de la globalización. Antes de la época del transporte aéreo, el desplazamiento a través de largas distancias era mucho más temible y la movilidad restringida limitaba el movimiento de las infecciones contagiosas. Por otra parte, antes de la comunicación electrónica, la muerte y la devastación causadas por brotes de enfermedades, hambrunas y catástrofes naturales no llegaban a penetrar en la conciencia de las personas ajenas a las regiones afectadas. A finales del Siglo XX, la población de la Tierra aumentó de 2 billones a un nivel actualmente estimado de más de 9 billones [7]; en consecuencia, existen en todo el globo muchas más victimas potenciales de enfermedades transmisibles. Todos éstos son factores emergentes, tangibles, con respecto al contexto de una pandemia actual como el SIDA.

De los 39 millones de personas que se estima infectadas en todo el mundo por el VIH, más de 25 millones (64\%) residen en África subsahariana. A diferencia de sus contrapartes del mundo más desarrollado, las personas infectadas por el VIH en África tienen menos probabilidad de experimentar años de buena salud y productividad antes del inicio del SIDA. Millones de africanos están enfermando y mueren prematuramente, no por falta de medicamentos avanzados, sino por problemas sanitarios evitables, causados en su mayoría por una nutrición deficiente. Actualmente, el VIH/SIDA afecta principalmente a personas del grupo de edad productiva. Esto ejerce un considerable impacto sobre los medios de vida y la seguridad alimentaria y nutricional debido a que reduce la mano de obra disponible [8].

El VIH/SIDA ejerce también un gran impacto temible sobre los niños y sobre los progresos logrados en la supervivencia infantil. Según Walker y Schwartländer [9], entre 1990 y 1998 el número de fallecimientos de niños menores de 5 años en África subsahariana, causados por la infección por VIH, se elevó del 2\% al 7.7\%. Cinco países presentan tasas de mortalidad de menores de 5 años atribuibles al VIH superiores al 30 por 1,000, mientras que las tasas de la mortalidad de menores de 5 años específicas del VIH en 16 países oscilan entre 10 y 25 por 1,000. El resto de los países en Africa, 18 en total, presentan tasas por debajo del 10 por 1,000 [9]. El impacto del VIH/SIDA en la mortalidad de niños menores de 5 años en África se está incrementando y, si bien no es la única causa, está contribuyendo a revertir las tendencias de supervivencia infantil. De acuerdo con uno de los estudios del USAID, el VIH/SIDA está dando la vuelta a años de desarrollo económico y social [10]. En el mismo estudio se menciona el hecho de que en 1990 el SIDA representaba el $16.4 \%$ de las muertes de padres con resultado de orfandad; en 2010, la cifra se incrementará hasta un mínimo del $68.4 \%$. A pesar de que estas cifras son asombrosas, no toman en consideración a los niños que viven con padres enfermos, que son los cuidadores principales de sus padres, de hermanos menores y otros, y a los niños responsables del mantenimiento de los medios de vida de la familia. Los niños en África se enfrentan con retos de un alcance y una complejidad nunca vistos anteriormente.

El 26 de junio de 1945 se crearon las Naciones Unidas en San Francisco, EE.UU. Con su formación, la pobreza, la miseria y las enfermedades dejaron de considerarse las consecuencias inevitables de la condición humana, y la desigualdad de la distribución de las riquezas dejó de ser tolerada como parte del orden social natural. En diciembre de 1948 se adoptaron las Declaraciones de Derechos Humanos en la Tercera Asamblea General de las Naciones Unidas. Su importancia para las personas que viven con el VIH/SIDA (PVVS) ha sido objeto de comentarios precisos [11]. Más recientemente se han enunciado los Objetivos del Milenio con respecto a la salud y al desarrollo; varios de éstos tienen una relevancia directa para el VIH/SIDA [12].

Estos son algunos de los contextos históricos esenciales que circundan la cuarta parte del siglo de la pandemia de SIDA. No obstante, el prisma para la mayoría de los profesionales de la salud y las autoridades de salud pública sobre cualquier cues- 
tión sanitaria no se establece a nivel macro-político. Más bien, se reduce al nivel de programas comunitarios o a los procedimientos cotidianos con pacientes y clientes. En consecuencia, consideramos que un enfoque a nivel de comunidad es interesante para los lectores de Annales Nestlé. 'Alimentos, asistencia y salud están ampliamente reconocidos como la sagrada trinidad de la nutrición', comentó Haddad [13] en el 17 Congreso Internacional de Nutrición de 2001. En nuestro tratamiento del tema 'VIH y las ramificaciones para la seguridad alimentaria y la salud infantil en las comunidades afectadas' buscamos proporcionar conocimientos sobre las interacciones bilaterales de la ingesta de comida y la asistencia en comunidades pobres frente a los impactos polifacéticos, biológicos, sociales y psicológicos, del padecimiento endémico del VIH.

\section{Interacción entre nutrición e infección}

La ingesta alimentaria inadecuada y las enfermedades infecciosas son las causas inmediatas más significativas de la malnutrición [8]. Dado que el VIH/SIDA es un complejo de una infección viral primaria (VIH) asociada a infecciones oportunistas (SIDA), la interacción entre desnutrición e infección es fundamental. En el reciente Informe sobre Alimentos y Nutrición para las Personas que Viven con el VIH/SIDA, del Departamento de Estado de EE.UU. [14], se afirma: 'El VIH/ SIDA y la malnutrición son sumamente prevalentes en muchas partes del mundo, especialmente en África subsahariana. Estos efectos están interrelacionados y se exacerban mutuamente en un círculo vicioso'.

\section{Conceptos y principios}

Las bases conceptuales y científicas de un asunto de interés a nivel biológico, por la inseguridad alimentaria y una enfermedad infecciosa, como el VIH, se establecieron hace casi medio siglo. Scrimshaw y cols. [15] documentaron una enorme miríada de interacciones entre hospedante y patógeno en la naturaleza, en las cuales el estado nutricional del hospedante condicionaba la respuesta a una infección y la presencia de una infección afectaba al estado nutricional del hospedante. Este conjunto de datos se amplió en 1968 en una monografía de series técnicas publicada por la OMS [16]. Por una parte, un hospedante mal nutrido era más propenso a infectarse cuando se exponía a un patógeno, o a sufrir una infección más prolongada o intensa con mayor probabilidad de ser letal. Ahora sabemos que la base general del efecto del estado nutricional está relacionada con la integridad y la función del sistema inmunitario defensivo del hospedante. La idoneidad del estado de los nutrientes podría influir sobre el éxito de la defensa del hospedante frente al patógeno $[17,18]$. Esto es así en cualquier nivel, desde la impermeabilidad de las barreras (piel, mucosas, revestimiento intestinal) que excluyen la penetración de microorga-

VIH, seguridad alimentaria y salud infantil nismos hasta las respuestas innatas de envolvimiento o destrucción de los microorganismos y otras respuestas adquiridas de reacciones mediadas por anticuerpos y la respuesta inflamatoria sistémica.

Por otra parte, un animal o una persona afectada por una infección, bien sea aguda o crónica, podría experimentar pérdida de peso y deterioro general del estado nutricional, así como el inicio de carencias específicas de vitaminas o minerales. Debemos recalcar que el término clásico de tuberculosis pulmonar era 'consunción'. En general, los estragos de una infección tienden a disminuir el estado nutricional de un hospedante reduciendo el apetito, bloqueando la absorción de nutrientes o causando la destrucción o el agotamiento de nutrientes en el organismo. Por ejemplo, la deshidratación aguda asociada a un ataque de gastroenteritis es el resultado de una combinación de todos estos mecanismos. Por otra parte, se conoce desde hace tiempo que un episodio de sarampión precede frecuentemente la forma más grave de malnutrición de proteínas y energía, el kwashiorkor. Ambas interacciones entre nutrición e infección mencionadas anteriormente se denominan 'sinérgicas'.

A la inversa, en algunos casos, un hospedante bien nutrido mostró una mayor resistencia a infectarse o sufrió un curso infeccioso más leve, mientras que un hospedante sobre-nutrido era más propenso a sufrir infecciones adversas que un hospedante normalmente nutrido. Estos son casos de una interacción llamada antagonista entre nutrición e infección. En las décadas de los 50 y los 60, la obesidad y el exceso nutricional no eran considerados problemas de salud pública importantes en países industrializados o en vías de desarrollo. Aunque la inmensa mayoría de las interacciones eran sinérgicas, un número seleccionado de relaciones entre nutrición e infección eran de naturaleza antagonista; es decir, la deficiencia de un nutriente ejercía un impacto protector frente a la infección o a los efectos de la infección por un microorganismo patógeno $[15,16]$. Esto ocurría habitualmente con patógenos intracelulares, esos agentes de enfermedad que invaden las células del hospedante y se alimentan de los nutrientes dentro del citosol. En tales casos, cuanto más abundantes sean las reservas de nutrientes en las células de un hospedante, más atractivas serán para el patógeno y más próspero y beneficiado se verá el microorganismo invasor.

\section{Sinergia de la infección sobre el estado nutricional en el VIH/SIDA}

La consideración más somera de lo que sabemos sobre la progresión del SIDA sindrómico ilustrará un ejemplo clásico de efectos nutricionales adversos de una infección, siendo la causada por el VIH la enfermedad subyacente primaria. El SIDA se caracteriza por un desgaste caquéctico [19] y fue denominado 'enfermedad de flaqueza' según la manera de expresión local de las zonas en las cuales se describió por vez primera en el continente africano. 
Por otra parte, las infecciones asociadas en la etapa del síndrome del SIDA, incluyendo infecciones convencionales como la tuberculosis, así como las llamadas infecciones 'oportunistas' (es decir, microorganismos que no son habitualmente patógenos en el hospedante nutrido normalmente), son patognomónicas del SIDA. Debido al VIH y sus infecciones asociadas, una persona que vive con SIDA es un individuo inapetente, con grados de anorexia de leves a intensos. Por ejemplo, Cryptosporidium parvum, un protozoo ubicuitario que no suele ser patógeno en el individuo inmunocompetente (o, en el peor de los casos, ocasiona un episodio diarréico que se resuelve espontáneamente en un niño pequeño), causa una infección intestinal persistente y prácticamente intratable, con una diátesis diarreica que puede generar dos litros de pérdidas fecales al día [20]. El SIDA se asocia a la activación crónica de la respuesta de fase aguda [21], caracterizada por fiebre y un cuadro metabólico que consume y agota macronutrientes y micronutrientes, dando lugar a la consunción visceral y muscular. Basándose en los efectos de depleción nutricional del VIH en todas sus etapas, es esencial suministrar nutrientes suficientes y hacer cuanto sea necesario para contribuir a retenerlos en el organismo.

\section{La sinergia del estado nutricional sobre la infección en el VIH/SIDA}

Bándose en los principios de la interacción entre nutrición e infección, en la época del VIH/SIDA se concibió inicialmente la esperanza de que mejorando el estado nutricional de poblaciones pobres y desnutridas se contribuiría a impedir la transmisión del virus, ya sea por vía sexual entre parejas que practican el coito [22] o por la vertical de la madre al lactante [23-25]. La esperanza de mitigar la transmisión sexual se suscitó y se examinó a pesar de las observaciones iniciales de que homosexuales bien nutridos, en naciones opulentas, eran la punta de lanza inicial de la pandemia de SIDA. En general, el aporte complementario de vitaminas o minerales (micronutrientes) para prevenir nuevas infecciones transmitidas sexualmente no produjo resultados positivos. Aspiraciones similares de mejorar el estado materno de micronutrientes para reducir la transmisión del virus desde la madre hasta el feto, el recién nacido o el lactante pequeño, fueron abrigadas por investigadores de intervenciones de campo; en el artículo de Downs y Cooper [26] se revisan los resultados de estas investigaciones.

Además, ciertas asociaciones entre la ingestión alimentaria de micronutrientes específicos y la progresión de infecciones por VIH a etapas sintomáticas y muerte [27-30] alentaron expectativas en sentido de que la mitigación de las carencias de micronutrientes podría paliar la infección, reduciendo su progresión o letalidad. El nutriente de mayor interés ha sido la vitamina A. Fawzi [31] revisa extensamente la amplitud y la profundidad de los diseños y los resultados de intervenciones experimentales a partir de estudios de campo relacionados con el estado de micronutrientes, el aporte complementario de los mismos y los desenlaces de VIH/SIDA.
Una posibilidad teórica, pero todavía no explorada, en la compleja relación entre el VIH y el estado nutricional del hospedante, sería un incremento en la virulencia del retrovirus. Un modelo para una situación de esta índole puede hallarse en el trabajo de Beck y cols. [32-35] en EE.UU. Estos autores hallaron que un virus de tipo coxsackie, que causa una infección respiratoria leve y transitoria en ratones bien nutridos, se transformaría por mutación en una cepa virulenta y letal tras su transmisión a un ratón hospedante en el que se hubiera provocado una deficiencia del oligoelemento selenio [32]. Por otra parte, el virus mutante llegaría a ser entonces virulento, causando infecciones letales en roedores portadores de un nivel adecuado de selenio. Se sospecha que el pase de otras cepas de virus a través de hospedantes con otros tipos de carencias de nutrientes puede causar también mutaciones, incrementando su virulencia [34]. Teniendo en cuenta las deficiencias humanas generalizadas de hierro, yodo, vitamina A y cinc, entre otras, que se dan en el mundo, es urgente considerar y explorar cualquier transformación potencial del VIH en hospedantes con reducción de micronutrientes.

\section{Antagonismo del estado nutricional sobre la infección en el VIH/SIDA}

Al igual que los virus, el retrovirus que causa el SIDA es un patógeno intracelular. Esto suscitaría el espectro de algunas formas de interacciones antagonistas en las que privar al VIH de un nutriente crucial para su desarrollo y proliferación podría retrasar la infección. Por otra parte, las infecciones asociadas en la etapa del síndrome de SIDA, incluyendo las llamadas infecciones 'oportunistas', tienden a proliferar en una localización intracelular.

Esto ha alentado un cierto número de consideraciones importantes. Una de ellas se refiere a la fortificación o suplementación rutinaria con un nutriente que podría favorecer la proliferación del VIH u otro patógeno invasor. En comunidades afectadas por la endemia de VIH/SIDA ¿tendría en general un efecto mixto la aplicación de programas demográficos amplios para mejorar el estado de micronutrientes de las masas? ¿Beneficiaría a algunos, por ejemplo a quienes fuesen VIH seronegativos con una carencia preexistente, pero a cuántos afectaría adversamente, por ejemplo a los seropositivos con o sin una carencia de nutrientes? Una interrogante de esta índole adquiere una importancia creciente como sucedió con la revelación del resultado del aporte complementario sistemático de hierro y ácido fólico (con o sin cinc acompañante) en niños pequeños de una región holoendémica de paludismo en la isla de Pemba, en Zanzíbar, Tanzania [36]. Los niños infectados de paludismo en ambos brazos del tratamiento con hierro y ácido fólico tendían a experimentar más hospitalizaciones y mortalidad que comparados con los que recibieron sólo cinc o los grupos control sin tratamiento (placebo).

La otra cara del problema guarda relación con lo que Weinberg [37] denominó 'inmunidad nutricional', es decir, la 
protección potencial transmitida por un estado nutricional marginalmente deficiente en un entorno de transmisión de un patógeno que depende de nutrientes. ¿Proporcionaría el conocimiento de las necesidades de nutrientes del VIH una manera de bloquear su proliferación privándolo del nutriente? ¿Resistiría la persona infectada por VIH infecciones oportunistas al ser nutrida más marginalmente con los nutrientes de interés para la bacteria causal o los microorganismos protozoarios?

Los oligoelementos mencionados anteriormente (hierro y cinc) han sido de interés en términos de riesgos potenciales a partir del consumo de cantidades superiores a las adecuadas, dando lugar a implicaciones para la seguridad y la prudencia de intervenciones al nivel de la población con estos nutrientes. En relación con el hierro, se ha propuesto un cierto número de razones teóricas de por qué depósitos de hierro corporales repletos albergarían microorganismos intracelulares, tanto patógenos como oportunistas [38]. No obstante, un ensayo de intervención reciente con aporte complementario de hierro, realizado en Kenia, no fue capaz de mostrar ningún efecto adverso sobre la carga de VIH [39].

Se ha establecido que muchos de los mecanismos víricos del VIH dependen del cinc. Por otra parte, en los estudios epidemiológicos de Tang y cols. se observó una mayor progresión de VIH a SIDA [27] y una supervivencia más corta a través de la fase de SIDA [28], antes del uso de los antirretrovirales, en hombres que consumían cantidades elevadas de cinc alimentario y complementario. En un estudio clínico reciente realizado en Durban, Sudáfrica, con algunos elementos de deficiencia ética, Bobat y cols. [38] exploraron la hipótesis de si la administración de $10 \mathrm{mg}$ de cinc elemental en pacientes juveniles afectados de SIDA, en un hospital de KwaZulu-Natal durante seis meses, influiría adversamente el curso de la infección. En el grupo asignado aleatoriamente al cinc no se observó aumento de la progresión ni mortalidad; de hecho, las respuestas observadas fueron beneficiosas. El otro ensayo fue publicado por Olsen y cols. [39] y se realizó en Kenia. Se monitorizó la carga vírica de VIH-1 durante cuatro meses de suplementación de $60 \mathrm{mg}$ de hierro dos veces por semana en mujeres gestantes seropositivas. No se observaron efectos sobre la carga vírica con ese hierro semi-semanal. Dado que las dosis de 60 a $120 \mathrm{mg}$ de hierro diarias son las dosis corrientes en la situación prenatal, los autores comentan que 'los efectos de dosis más altas de hierro no pueden ser excluidos' [39].

Los resultados de los ensayos mencionados anteriormente pueden interpretarse como generadores de cierta garantía con respecto a la seguridad de incluir niños VIH positivos en la cobertura de aportes complementarios de hierro o cinc o en programas de fortalecimiento. No obstante, las consideraciones teóricas de interacciones del hierro y el cinc con el VIH u otros microorganismos infectivos en el síndrome del SIDA [39, 40] abogan a favor de vigilancia y monitorización constantes para cualesquiera indicaciones contrarias a las estudiadas en sólo dos ensayos respectivos.

VIH, seguridad alimentaria y salud infantil
Tabla 1. Declaración de la opinión de la Asociación Dietética Norteamericana y Bromatólogos de Canadá sobre la intervención nutricional en la asistencia de personas infectadas por el virus de la inmunodeficiencia humana

La infección por el virus de la inmunodeficiencia humana (VIH) y el desarrollo del síndrome de inmunodeficiencia adquirida (SIDA) han ejercido un impacto significativo sobre los desenlaces sanitarios, sociales, políticos y económicos, tanto domésticos como globales. Los esfuerzos de prevención y tratamiento para controlar la infección por VIH son más exigentes que en décadas anteriores. La consecución de la seguridad alimentaria y nutricional y el manejo de las complicaciones de las infecciones de VIH relacionadas con la nutrición y los múltiples aspectos de la enfermedad iniciada por la infección del VIH, o en torno a la misma, que se designa como enfermedad por VIH, sigue suponiendo un reto para los pacientes y las personas implicadas en los esfuerzos de prevención, asistencia y tratamiento del VIH/SIDA. Entre las cuestiones clínicas engañosas destacan las siguientes: interacciones medicamentosas, infección concomitante con otras infecciones y enfermedades, consunción, lipodistrofia y otras.

De Fields-Gardner y Fergusson [44].

\section{Seguridad e inseguridad alimentarias en comunidades afectadas por VIH/SIDA}

En 2001, el entonces director del UNAIDS, Dr. Peter Piot, afirmó que la preocupación más insistente de las PVVS a las que él había visitado, era tener alimentos suficientes [41]. Whiteside y cols. [42] destacaron una importante realidad con respecto a la evolución de la enfermedad, consistente en que el prolongado periodo de incubación entre la infección y la enfermedad conlleva una serie de consecuencias; con esto quiso decir que 'se necesita tiempo para que las infecciones por VIH se conviertan en casos de SIDA y los casos de SIDA se traduzcan en desenlaces mortales con todas las consecuencias de orfandad, pobreza y estructuras demográficas cambiantes'. No obstante, ahora que han transcurrido 25 años desde el inicio de la epidemia de VIH/SIDA comenzamos a examinar estas consecuencias en el contexto del efecto sobre la seguridad alimentaria de poblaciones afectadas. Tabi y Vogel [43], investigadores de enfermería que prestan sus servicios en Ghana, expresan un punto de vista inquietante: 'en Ghana, igual que en numerosos países en vías de desarrollo, fallecen más pacientes con VIH y SIDA por su deficiente estado nutricional que por la enfermedad propiamente dicha'. Aunque procedentes de las dos naciones más opulentas de Norteamérica, el texto de la declaración de opinión de 2004 de las asociaciones dietéticas de EE.UU. y Canadá (tabla 1) [44] transmite el conjunto exhaustivo y global de asuntos que impactan sobre la seguridad alimentaria y la asistencia infantil a lo largo de todo el mundo en el siglo XXI.

Ann Nestlé [Esp] 2007;65:9-28 


\section{Definiciones de seguridad alimentaria y medición de la inseguridad alimentaria}

De conformidad con la Declaración de Roma y el Plan de Acción Cumbre Mundial sobre Alimentos, de la Organización de Alimentos y Agricultura, existe un estado de seguridad alimentaria 'cuando todas las personas, en cualquier momento, tienen acceso a alimentos suficientes, seguros y nutritivos para satisfacer sus necesidades dietéticas y sus preferencias alimentarias para una vida activa y sana' [45]. El estado de 'inseguridad alimentaria' sería una situación en la que no se cumplen los criterios de definición mencionados anteriormente. Una definición abreviada sería la de 'acceso limitado o incierto a suficientes alimentos nutritivos' [46]. Los focos de preocupación con respecto a la seguridad alimentaria pueden ser diversos, tanto a nivel nacional, local (comunidad), familiar (hogar) incluso como individual. Esto se basa, como es lógico, en la cantidad de alimento disponible en los diversos niveles. Además, con una distribución irregular de un suministro insuficiente de alimentos, algunas personas podrían satisfacer su seguridad alimentaria, si bien su generalización equitativa a 'todas las personas' exigiría la presencia de alimento suficiente en un país para cubrir las necesidades de todos sus residentes.

Diversas instituciones e individuos han intentado operacionalizar las definiciones en formatos para evaluar la seguridad alimentaria y diagnosticar un estado de inseguridad. La Organización de Alimentos y Agricultura en el Sistema de las NU recopila y tabula fichas técnicas de equilibrio de alimentos en la mayoría de los países, a partir de las cuales se puede determinar un estado de 'desnutrición' en una nación cuando el número de calorías de energía alimentaria producidas o importadas es insuficiente para cubrir las necesidades de la población. La FAO ha insistido habitualmente en una definición minimalista basada en la ración esencial mínima [45]. Otros son más elaborados y ambiciosos en sus exigencias. Por ejemplo, Gopalan [47] comenta: 'El logro de seguridad nutricional en el nivel doméstico implica la idoneidad del suministro de alimentos al nivel nacional y la distribución equitativa de alimento entre la población en consonancia con sus necesidades fisiológicas'.

Para términos más prácticos y de investigación relacionados con el VIH/SIDA, el nivel doméstico (o individual) sería el centro de preocupación más apropiado para la seguridad alimentaria. Los instrumentos para evaluar la seguridad alimentaria en el entorno de campo se remontan a principios de la década de los $90[48,49]$, incluyendo la recolección de información sobre características demográficas, frecuencia de consumo de frutas y verduras y suministros de alimentos al hogar. La validación cruzada frente a otros indicadores de insuficiencia alimentaria en los ámbitos domésticos rurales de EE.UU. encontró altos grados de sensibilidad y especificidad en el diagnóstico de la inseguridad alimentaria. En otro frente, aunque se propone la diversidad dietética como posible indicador de la seguridad alimentaria y factor pronóstico del estado nutricional, se necesita más investigación para estandarizar definicio- nes y metodología antes de que pueda aplicarse ampliamente [50]. Hasta la fecha se han propuesto herramientas adicionales para medir la seguridad alimentaria en el nivel doméstico; estas herramientas son fiables en encuestas demográficas, y en algunos estudios se ha hallado que las mediciones de la seguridad alimentaria se asocian a la ingestión de nutrientes [51].

A pesar de la validación y la validez de elaboración de cuestionarios de campo en determinados ámbitos, la evaluación de la 'inseguridad alimentaria' no está exenta de sus paradojas. Rose [52] examinó indicadores de seguridad alimentaria en una muestra representativa a nivel nacional de la población de EE.UU., hallando que la mayoría de los miembros de las familias clasificadas como insuficientes en alimentos comunicaban ingestas diarias menores que las correspondientes a hogares alimentariamente suficientes, si bien esta pauta no regía para los miembros de las familias en edad preescolar. Por otra parte, la prevalencia del estado de sobrepeso infantil se está incrementando. Tal como se ha medido en la Escala de Seguridad Alimentaria de EE.UU., se ha asociado una mayor inseguridad alimentaria con el estado de sobrepeso infantil en adolescentes femeninas de edades comprendidas entre 12 y 17 años [46]. No obstante, utilizando en el área rural de Malasia el mismo instrumento validado en el estado de Nueva York [48, 49], Shariff y Khor [53] también registraron el dato aparentemente paradójico de más sobrepeso y obesidad (50\%) en mujeres alimentariamente inseguras en comparación con el $38 \%$ de las mujeres pertenecientes a familias alimentariamente inseguras. El incremento de los perímetros de la cintura siguió la misma asociación.

En consecuencia, recientemente ha tenido lugar un movimiento correctivo para revisar los objetivos de evaluación de la seguridad alimentaria, su conceptualización y su medición [54]. La perspectiva general realza tres desarrollos conceptuales principales asociados a enfoques prácticos para medir las limitaciones en el acceso al alimento: (1) una desviación del uso de mediciones de la disponibilidad y utilización de alimentos para medir un 'acceso inadecuado'; (2) una desviación de un enfoque sobre mediciones objetivas a subjetivas, y (3) un énfasis creciente sobre la medición fundamental en oposición a una dependencia de mediciones distales, sustitutivas. Webb y cols. [54] describen una agenda de cuatro puntos (tabla 2) para el desarrollo y el refinamiento de la medición de la seguridad alimentaria. Teniendo en cuenta los elementos paradójicos de los enfoques tradicionales descritos anteriormente y la profundidad conceptual más rica, este nuevo enfoque, una vez desarrollado, parecería ofrecer más promesa y aplicación en relación con el impacto del VIH/SIDA.

\section{Vulnerabilidad de las comunidades pobres}

Las comunidades pobres en países en vías de desarrollo presentan un riesgo máximo de aumento de la incidencia y la prevalencia del SIDA $[55,56]$. La pobreza también transmite vulnerabilidad a la ingestión inadecuada de alimentos, el de- 
terioro del estado nutricional y la limitación de la asistencia de salud $[57,58]$. La transmisión del VIH en estas frágiles circunstancias de pobreza rural y urbana ha avasallado y/o destrozado por completo los mecanismos existentes antes de la aparición de la pandemia del SIDA.

El VIH y el SIDA afectan a todos los elementos de la sociedad, no sólo a los infectados directamente y los que viven con el virus. Tal como describieron Whiteside y cols. [42] conllevan también otras características únicas: 'El prolongado periodo de incubación entre la infección y la enfermedad significa que toma tiempo para que las infecciones por VIH se conviertan en casos de SIDA y para que los casos de SIDA se traduzcan en muerte, con todas las consecuencias de orfandad, pobreza y estructuras demográficas cambiantes. Además, significa que una vez que la prevalencia del VIH ha alcanzado el máximo, necesitará años para abrirse paso a través del impacto del SIDA; esta epidemia es un evento de una 'gran ola'. En consecuencia, una perspectiva intergeneracional y del curso de la vida es importante para afrontar la manifestación local de la pandemia'. Por lo menos en África, donde se encuentra el mayor número de PVVS, la inseguridad alimentaria es también extremadamente problemática, con predicciones sombrías en su mayoría, en lo que respecta a la pobreza persistente y expansiva. Según Rukuni [59], 'África sigue siendo la única región en el mundo donde el número de personas hambrientas estará aumentando todavía en el 2020 y el número de niños mal nutridos aumentará en forma correspondiente'.

\section{Factores que condicionan la seguridad alimentaria de las personas que viven con VIH/SIDA}

Independientemente de las advertencias y las limitaciones que pudiera tener la medición precisa de la inseguridad alimentaria, lo que sigue representa una revisión de las condiciones y los factores dentro del seno de entornos y sociedades que amenazan o protegen el acceso y la disponibilidad de alimentos de las comunidades. La intersección de estos factores con individuos y/o familias infectadas por VIH es un asunto de estudio académico incipiente.

\section{Pérdidas de capital humano y productividad agrícola}

La cantidad de alimento disponible en un país es un producto de la agricultura y horticultura o del comercio internacional. Con respecto al comercio, la capacidad para importar depende de la riqueza generada por las exportaciones, que es una función, a su vez, de los recursos naturales y humanos convertidos en bienes y servicios de utilidad. En relación con la agricultura y la horticultura, la escala de producción varía desde extensiones grandes hasta parcelas de subsistencia familiar. En cualquier nivel, el VIH/SIDA ha tenido una serie de consecuencias adversas sobre las actividades agrícolas. Saasa [60] ha enumerado esas consecuencias a partir de la perspectiva de una experiencia africana (tabla 3 ).

VIH, seguridad alimentaria y salud infantil
Tabla 2. Necesidades de investigación adicionales en la evaluación de la seguridad y la inseguridad alimentaria

1 Grado en el cual las mediciones de la inseguridad alimentaria doméstica, diseñadas para contextos de inseguridad alimentaria crónica, captan los procesos conducentes a la inseguridad alimentaria aguda, y la experiencia con ésta

2 El impacto de catástrofes a corto plazo, como inundaciones importantes o terremotos, sobre los comportamientos domésticos que determinan las respuestas a preguntas de seguridad alimentaria

3 Mejora de la medición de la interacción entre la gravedad y la frecuencia de las conductas de inseguridad alimentaria domésticas

4 Determinación de si una respuesta individual, a preguntas de encuesta, puede ser representativa de experiencias con la inseguridad alimentaria de todos los miembros de la familia

De Webb y cols. [54].

Tabla 3. Consecuencias de la pérdida de la mano de obra productiva sobre la productividad agrícola

1 Reducción del uso de la tierra para cultivo, dado que la gente está físicamente incapacitada para trabajar en el campo

2 Reducción de los rendimientos de las cosechas, debido a los retrasos en la realización de ciertas intervenciones agrícolas como cambios en la rotación de modalidades de cultivo

3 Cambios en las modalidades de cultivo, dado que algunas familias han cambiado a cosechas de trabajo menos duro

4 La disminución del margen de cosechas por hogares o familias afectadas por el SIDA reduce el número de cosechas a una sola cosecha principal

5 Reducción de la capacidad para controlar las plagas, como escardar las malas hierbas y otras medidas en los cultivos, debido a la merma de trabajo

6 Pérdida del conocimiento agrícola y de las habilidades para gestionar las granjas debido a la pérdida de uno o ambos padres por SIDA

7 Declinación de la producción de animales de cría, dado que la urgente necesidad de obtener dinero en efectivo puede obligar a algunas familias a vender los animales

Modificado de Saasa [60].

La primera de las consecuencias enumeradas que se relacionan en la tabla 3, concretamente la reducción de los bienes humanos en términos de trabajo y la reducción consecuente del uso de la tierra, es la mencionada más corrientemente. Tal como comentó Rutengwe [8]: 'Actualmente, el VIH/SIDA afecta 
principalmente a personas del grupo de edad productiva. Esto ejerce un impacto considerable sobre la subsistencia y la seguridad alimentaria y nutricional debido a que causa una retracción de la mano de obra disponible'. Adicionalmente, el trabajo disponible disminuye a medida que los individuos sanos tienen que cuidar de los infectados y acudir a los funerales de los fallecidos. Los niños son obligados a dejar la escuela prematuramente, por lo que obtienen menores niveles educativos. Además, con la muerte prematura de trabajadores adultos se produce una pérdida de conocimiento autóctono entre generaciones, así como del 'aprender practicando' bajo la supervisión de alguien más experimentado. Según la FAO de las Naciones Unidas, han fallecido más de siete millones de trabajadores de extensiones agrícolas en 25 países subsaharianos y se prevé que mueran 16 millones más en las próximas dos décadas.

El debilitamiento de la mano de obra por el VIH/SIDA puede afectar adversamente a la capacidad de una nación para producir su propio alimento y/o importarlo. Otras varias consecuencias más pueden ser ilustradas con ejemplos de la literatura reciente. Ya en 1993, sólo 12 años desde la aparición de la epidemia del VIH/SIDA, en un estudio retrospectivo realizado en los dos distritos más fértiles de Uganda, se documentó una declinación del uso de la tierra en el 66\% de las familias encuestadas, con declinaciones del $11 \%$ y el $32 \%$ en la producción de aves de corral y ganado, respectivamente, atribuidas a la mala gestión [60]. Los motivos descritos más frecuentemente por las reducciones de las cosechas fueron las muertes y las enfermedades que, según se estimó, afectaron al $8 \%$ de las familias con niños menores de 5 años en la zona en estudio. Por otra parte, en este contexto, la pobreza ha reducido el empleo de pesticidas, herbicidas y fertilizantes [61].

Tal como describen Gillespie y cols. [62], la aparición del VIH/SIDA ha causado otros impactos sobre el uso de la tierra, incluyendo el cultivo de cosechas menos nutritivas (por ejemplo, ciertos tubérculos), que exigen menos trabajo. Aunque abstenerse de elaborar la tierra hará que ésta sea más fértil para el crecimiento de futuros cultivos, suponiendo que la familia pueda permitírselo, las familias en general pueden llegar a ser más vulnerables a la pérdida de los derechos sobre sus tierras, especialmente las mujeres y los huérfanos. El capital natural y físico se pierde a medida que las familias se ven obligadas a vender los bienes de producción (es decir, equipo y herramientas), así como los animales de cría, para pagar gastos médicos y de funerarias, lo que hace casi imposible el regreso al trabajo agrícola. Además, otras fuerzas en juego ejercen un impacto negativo sobre la productividad agrícola, destacando entre ellas la sobrepoblación y la subdivisión de la tierra por herencia, tal como se vive en Uganda [61].

En una faceta relacionada con la cuestión de la productividad agrícola, las exigencias del estilo de vida agrario rural, con tareas domésticas que suponen un trabajo pesado e intensivo y una limitación en el tiempo, han sido también identificadas como una barrera frente a la participación de las mujeres etíopes en la educación para la prevención de enfermedades de transmisión sexual [63].

\section{Problemas domésticos en la obtención de alimentos}

Las mujeres forman parte de la mano de obra en entornos africanos endémicos de SIDA, tanto rurales como urbanos. En un estudio realizado en mujeres casadas en Malawi, Zimbabue y Zambia, al examinar los factores que influían sobre el estado nutricional materno en zonas afectadas por el VIH/SIDA y propensas a las sequías [64], se obtuvieron datos geográficamente variables. El riesgo de deficiencia energética crónica (DEC), definida como la presentación de un índice de masa corporal $<18.5 \mathrm{~kg} / \mathrm{m}^{2}$, fue mayor en mujeres de Malawi, con menor poder de toma de decisiones en la familia, así como en mujeres urbanas de Zambia. En Zimbabue no se encontró asociación alguna entre la composición corporal y el poder de tomar decisiones. La conclusión del autor era que 'mujeres con bajo consumo y DEC pueden perder capacidad productiva, lo que las lleva potencialmente a un mayor riesgo de inseguridad alimentaria y VIH/SIDA en entornos de prevalencia elevada' [64].

La seguridad alimentaria doméstica puede quedar comprometida debido a una falta de recursos financieros e infraestructura y la asignación defectuosa de recursos domésticos entre familias de labradores sudafricanos pobres, incluso en ausencia de achaque parental por enfermedad [65]. La inseguridad resultante ejerce un impacto negativo, especialmente en niños, con la consecuencia de que la mitad de ellos llegan a estar subnutridos, con incapacidad para crecer o demacrados. Estos datos proceden de un estudio en el que se destacan las condiciones míseras de vida de familias de labradores en comunidades agrícolas de la provincia nor-occidental de Sudáfrica [65], aunque tales condiciones no se diferencian de situaciones que se observan en todo África subsahariana.

La marginación y el estigma sociales, que singularizan a los individuos y a sus familias en un sentido de discriminación y evitación, son factores que reducen la capacidad de una familia para obtener alimento. Aunque el estigma de la infección de SIDA varía de una comunidad a otra y de una sociedad a otra [63, 66-70], en general se rehuye a los individuos afectados. Incluso si éstos tienen la capacidad física para realizar trabajo productivo, hay una exclusión diferencial de la mano de obra de los sujetos infectados por VIH [67], mientras que vecinos y consumidores pueden abstenerse de los productos elaborados en sus casas. En el seno de una sociedad por lo demás pobre, las familias que viven directamente con el VIH llegan a ser las paupérrimas de entre las pobres, lo que limita su acceso a recursos financieros para proporcionar a la familia alimentos y otras necesidades básicas [66].

Tal como se ha comentado anteriormente, las pérdidas de capital humano arrasan la producción agrícola. Lo mismo cabe afirmar en los entornos de economía de subsistencia. El cultivo de parcelas de tierra individuales para producir alimentos para el consumo doméstico se torna cada vez más difícil a medida que se deteriora la salud de los miembros infectados de la familia, lo que debilita la salud, la resistencia y la energía [71]. No se puede prestar atención a las actividades de campo y las tierras entran en abandono. 
Además de las pérdidas de capital humano, natural y físico, las familias sufren también importantes pérdidas de capital financiero. La combinación de problemas relacionados con el estigma, con respecto al rechazo de créditos bancarios formales, o de iniciativas microfinancieras colectivas, además de la dificultad de conseguir jornaleros, causa tensiones financieras adicionales para las familias afectadas de VIH/SIDA. Como medida desesperada, las familias se ven forzadas a pedir prestado a prestamistas irregulares, que cobran intereses exorbitantes [62].

Con respecto a las cargas financieras impuestas a las PVVS, algunos datos de estudios de casos son ilustrativos. En un trabajo publicado, realizado en Chad en 2004, se menciona que los gastos a nivel doméstico atribuibles al SIDA - hasta el momento de la muerte - eran de USD 836 por caso [72]. Los gastos relacionados con las pérdidas de productividad representan el $28 \%$ de los costos totales. Más de la mitad de los costos totales (56\%) correspondió a gastos relacionados con la asistencia sanitaria, contribuyendo los costos funerarios con un 16\%. Los casos de SIDA dependen más frecuentemente de los préstamos y la venta de los bienes de las familias que de los controles terapéuticos. Los gastos domésticos de los pacientes con SIDA fueron muy superiores que los de las familias de control, debido principalmente a los desembolsos relacionados con la salud.

\section{Problemas domésticos en relación con la alimentación de}

los lactantes y los niños pequeños

En términos de alimentación de los lactantes y los niños pequeños, donde aparentemente la leche materna no genera ningún gasto financiero, las necesidades energéticas de las madres lactantes aumentan en aproximadamente $500 \mathrm{kcal}$, en comparación con las mujeres no gestantes ni lactantes de la misma edad [73]. Aunque no se han establecido necesidades adicionales para la lactancia, más allá de las necesidades adaptadas para el VIH [74], si la disponibilidad de calorías para el sustento básico constituye un problema, la obtención de alimentos adicionales para sustentar adecuadamente las $500 \mathrm{kcal}$ adicionales para la lactancia puede representar el 'golpe de gracia' para los mecanismos de medra financiera de una familia.

Si la obtención de alimentos extra para la madre constituye un reto, el hecho de pagar por alimentos especiales destinados al lactante es incluso todavía más prohibitivo. En las comunidades más pobres, la venta de leches artificiales adecuadas para lactantes puede no estar disponible o, en caso contrario, puede no ser accesible ni asequible para las familias que escogen esta opción como respuesta a la infección por VIH materna [75]. Si una madre elige abstenerse del amamantamiento y opta por una alimentación con una leche sustitutiva para lactantes, el coste añadido de la leche para lactantes y los suministros plantea una carga considerable para los recursos de la familia. Por otra parte, teniendo en cuenta las limitaciones higiénicas, la seguridad de la leche para lactantes preparada en situaciones higiénicas precarias representa una preocupación [76], con la perspectiva de más episodios diarreicos en los niños. Esto im-

VIH, seguridad alimentaria y salud infantil pone más esfuerzos en la asistencia de los niños, los costes de medicamentos y un incremento del riesgo de mortalidad infantil, que se añade a los 'costes' globales en sí de la abstención del amamantamiento. Por último, toda inversión especial en la leche para el lactante reduce los recursos de alimentación de los hermanos mayores.

La provisión del 'alimento de destete' es la siguiente etapa de la evolución alimentaria del niño en la que puede mediar la seguridad alimentaria. Las dietas ofrecidas a los lactantes en familias pobres, para complementar o sustituir la leche materna, son monótonas y difíciles de manejar, y en raras ocasiones cubren el déficit generado por la omisión de la leche materna en el suministro de la energía y los nutrientes requeridos para sustentar a un crecimiento rápido, la formación de depósitos de nutrientes y asegurar la resistencia a la infección [50]. La pauta de crecimiento y la prevalencia de malnutrición observadas desde el nacimiento hasta los cinco primeros años en África subsahariana son indicativas de las carencias de nutrientes en la dieta y la aparición de infecciones.

\section{Consumo alimentario de personas y comunidades que viven con el VIH/SIDA}

Los problemas de consumo alimentario en relación con la inseguridad alimentaria y el metabolismo biológico son diversos. Los resultados de las encuestas sobre la idoneidad alimentaria varían en función del entorno. Por ejemplo, en Boston, Mass., EE.UU., la idoneidad alimentaria de los macro- y los micronutrientes, basada en la evaluación cuantitativa de registros dietéticos de tres días, era en general aceptable entre las personas que abusaban de drogas intravenosas, tanto VIH positivas como VIH negativas; no había distinción entre ambos subgrupos [77]. No obstante, la equivalencia de las ingestiones puede no ser suficiente, teniendo en cuenta una falta de equivalencia documentada de las necesidades de nutrientes. Según la OMS [73], los individuos VIH positivos tienen una necesidad energética superior en un $10 \%$ para mantener el peso y la actividad física, mientras que los afectados de infección sintomática presentan necesidades energéticas del 20 al 30\% superiores para sustentar el mantenimiento del peso en la edad adulta. Un índice de masa corporal menor en el grupo VIH positivo fue atribuido más a las exigencias metabólicas de la enfermedad que a factores de restricción alimentaria [77]. Se estima que, en el caso de los niños, puede haber una necesidad del 50 al 100\% de energía adicional para restablecer la pérdida de peso [73].

Además, en un nuevo estudio publicado por HIV Medicine se halló que la malnutrición en el momento del inicio del tratamiento antrirretroviral está asociada a una supervivencia significativamente menor. Los pacientes con malnutrición presentaban un incremento de la mortalidad 6 veces superior en comparación con los pacientes bien nutridos [78]. El VIH y la malnutrición actúan en un círculo vicioso que debilita al sistema inmunitario y al organismo a través de infecciones repetidas.

Ann Nestlé [Esp] 2007;65:9-28 
No obstante, la ingesta alimentaria en pacientes infectados por VIH no está exenta de sus aspectos paradójicos. Kim y cols. [79] encuestaron una población de adultos infectados por VIH en EE.UU. Un 33\% estaban a dieta para perder peso. Las personas no de raza blanca y los usuarios de drogas inyectadas consumieron menos energía que las personas de raza blanca o las que no se inyectaban drogas. Las mujeres sin náusea y vómito consumieron más energía. Una proporción significativa de la cohorte en estudio (52\%) consumió menos de la ingesta diaria recomendada de vitamina $\mathrm{A}$, $\mathrm{y}$ una ingesta insuficiente de proteínas en un $11 \%$. Es evidente que la literatura actual sobre ingestión alimentaria se centra en países opulentos y que es imprescindible contar con más datos empíricos de poblaciones de entornos de países en vías de desarrollo.

\section{Mitos y paradojas en la relación entre inseguridad alimentaria $y \mathrm{VIH} / \mathrm{SIDA}$}

Existe un cierto número de mitos y paradojas en torno al problema de la inseguridad alimentaria y el VIH/SIDA. Es importante reconocerlos y evitar que confundan la política y el programa.

\section{Abordaje de los mitos}

Se ha observado que situaciones conflictivas como las que se dan en Costa de Marfil interrumpen el sistema de asistencia sanitaria e interfieren con los esfuerzos para prevenir la transmisión del VIH y atender a las personas infectadas [80]. ¿Qué significará la inseguridad alimentaria en la transmisión de la enfermedad? En un análisis del Alto Comisionado para los Refugiados de Naciones Unidas, Spiegel [81] afirma que: 'El conflicto, el desplazamiento, la inseguridad alimentaria y la pobreza contribuyen a que la población afectada sea más vulnerable a la transmisión del VIH. Sin embargo, la hipótesis común de que la vulnerabilidad se traduce necesariamente en más infecciones por VIH y, en consecuencia, alimenta la epidemia de VIH/SIDA, no está verificada por datos'. Si esto fuera cierto, la resolución de los problemas de inseguridad alimentaria, que son el objeto de esta revisión, puede ser claramente paliativa y mitigar el sufrimiento del infectado. Sin embargo, en caso contrario, no contribuye a detener el avance de la transmisión vírica en sí.

\section{Abordaje de las paradojas}

Tal como se ha comentado anteriormente, las medidas de inseguridad alimentaria doméstica pueden asociarse a obesidad. Análogamente, a pesar de la imagen del SIDA como 'enfermedad de delgadez', factores ambientales, conductuales y medicamentosos pueden favorecer los estados de exceso de peso. En las regiones urbanas de África, la base del sobrepeso puede llegar a ser el contexto para la extensión del VIH/SIDA. En el estudio de Transición y Salud durante la Urbanización de Sudáfrica, se encontró que la urbanización en la provincia noroccidental de Sudáfrica se acompañaba de una mejora de las ingestiones y el estado de micronutrientes, aunque también de incrementos de sobrepeso, obesidad y diversos factores de riesgo de enfermedades no transmisibles [82]. La aparición creciente de enfermedades no transmisibles en sudafricanos de raza negra, agravada por la pandemia de VIH/SIDA, presenta un cuadro complejo para los profesionales sanitarios y los forjadores de políticas [83].

El factor es la expansión de la medicación anti-VIH al pobre. Los efectos adversos de ciertos tratamientos para el VIH y los trastornos infecciosos asociados incrementan el riesgo de aparición de diabetes, obesidad y síndrome metabólico; en consecuencia, los tratamientos deben seleccionarse cuidadosamente, considerando con especial atención el riesgo de enfermedades cardiovasculares [84]. Investigadores de Filadelfia, EE.UU. [85], establecieron la siguiente conexión interesante: (1) que la obesidad predispone a las personas a contraer diabetes y enfermedad cardiovascular, y (2) que éstas son también las complicaciones asociadas al VIH, su tratamiento o ambos. Comprobaron que, en la época terapéutica, la obesidad (14\%) y el sobrepeso (31\%) eran más corrientes que la consunción (9\%) en su población clínica de Filadelfia [85]. En el subgrupo de mujeres, la prevalencia de obesidad era del $28 \%$. La prevalencia de obesidad central era del $45.7 \%$ en un grupo de personas que recibían tratamiento antirretroviral altamente activo para controlar las infecciones por VIH en Sao Paulo, Brasil, y se asociaba al mayor consumo de lípidos; por cada $10 \mathrm{~g}$ de incremento en la ingestión de lípidos, la probabilidad de obesidad central aumentaba 1.3 veces [86].

\section{Respuestas de la política y el programa a la inseguridad} alimentaria que afecta a las PVVS y a sus familias $y$ comunidades

Rosegrant y Cline [87] comentan lo siguiente en su destacado artículo del 2003 publicado en Science: 'La seguridad alimentaria global seguirá siendo una preocupación mundial durante y más allá de los próximos 50 años. Recientemente, el rendimiento de las cosechas ha descendido en numerosas zonas debido a la declinación de las inversiones en investigación e infraestructura, así como al incremento de la escasez de agua. El cambio climático y el VIH/SIDA son también factores cruciales que afectan a la seguridad alimentaria en muchas regiones'. La Asesoría de la OMS sobre necesidades de nutrientes para las PVVS subrayó una 'urgente necesidad de renovar el enfoque y el uso de los recursos para la nutrición como parte fundamental de los amplios paquetes asistenciales al nivel de países' [74]. La seguridad alimentaria disminuye cuando los sistemas alimentarios subyacentes están sometidos a tensión [88]. Entre los 'golpes de gracia' hay elementos de cambio ambiental, incluyendo situaciones conflictivas y VIH/SIDA; éstos pueden ser particularmente graves cuando los factores aparecen combinados, como en África meridional durante la última década. Por lo tanto, es importante considerar los aspectos de la inseguridad alimentaria al nivel global, nacional y comunitario, así como a nivel familiar/individual, en el contexto de la pandemia de VIH/SIDA. 
Consideraciones de política general en la mitigación de la inseguridad alimentaria

En la medida en que se espera cada vez más que las opciones políticas y las operaciones programáticas dependan de una base de evidencia de su eficacia, seguridad y eficiencia, la búsqueda de dicha evidencia no ha satisfecho a todos hasta la fecha. En el informe del Departamento de Estado de EE.UU. se comenta lo siguiente: 'Aunque se dispone de un número creciente de intervenciones para abordar la inseguridad alimentaria en poblaciones con una elevada tasa de VIH/SIDA, la evidencia empírica de la eficacia de dichos programas en la mejoría de los resultados de nutrición y salud, o el acceso sostenible a la utilización de alimentos por las poblaciones seleccionadas, es escasa' [14]. No obstante, uno llega a convencerse rápidamente por el contexto y la experiencia de que la búsqueda de medidas generalizables puede ser fútil y que, igual que la política, la mayor parte de la orientación para abordar el VIH/ SIDA es local.

Gillespie [89] ha resumido los tres principios dominantes y encauzadores para una estrategia exhaustiva para abordar los problemas de inseguridad alimentaria que emanan en el contexto del VIH/SIDA. Estos principios son los siguientes: (1) fortalecimiento de la resistencia de la familia y la comunidad al VIH y flexibilidad frente al SIDA; (2) mantenimiento e incremento de oportunidades de medios de vida en las comunidades afectadas, y (3) garantía de una protección social adecuada. No obstante, él advierte que la movilización no debe ser separada y desprendida específicamente para la crisis de VIH/ SIDA, sino más bien construir las soluciones a través de las comunidades enteras. Saasa [60] ofrece una filosofía similar de corte transversal, y hace un llamado a resolver los problemas subyacentes de pobreza y desarrollo estancado en zonas rurales de los países afectados, especialmente en África subsahariana.

Según Gillespie y cols. [71], entre los principios de la política destacan los siguientes: identificación de los recursos; atención a la aplicación y a la escala; asociación de los interlocutores apropiados en la colaboración; planificación y programación para urgencias sobrepuestas, así como monitoreo y evaluación. En cuanto a las intervenciones específicas relevantes para la seguridad alimentaria dentro de la epidemia de VIH/SIDA, las prioridades a tratar son el fortalecimiento orientado a los sectores de agricultura, hogar y huertas comunitarias, ayuda alimentaria, agua, higiene y salud ambiental, así como la gestión de los recursos naturales basada en la comunidad [90, 91].

En consecuencia, un enfoque concertado sobre la pobreza y la desigualdad en sociedades afectadas por el VIH/SIDA servirá para abordar las consecuencias de la infección. Esto es lo que Gillespie $[90,91]$ denomina 'corriente principal' del VIH/ SIDA, haciendo de su reparación parte de la reparación de los problemas comunitarios. Esta es una de las tácticas para actuar de manera efectiva sin estigmatizar a los beneficiarios. Puede ser fomentado proporcionando las capacidades apropiadas e induciendo su aplicación con incentivos razonables [90, 91].

VIH, seguridad alimentaria y salud infantil

\section{Apoyo y desarrollo agrícola para mitigar la inseguridad} alimentaria

En un sentido muy amplio, la intervención agrícola incluiría los huertos domésticos y las huertas comunitarias, así como la siembra de productos agrícolas y la crianza de animales para generar ingresos y sustento nutricional. La horticultura se centra en la diversidad dietética y en el enriquecimiento de la ingestión dietética con micronutrientes esenciales. Dado que la horticultura puede ser nueva para una comunidad, deben hacerse esfuerzos para la formación y capacitación de la comunidad para la implementación con respecto a la creación de huertas, así como para cambios de comportamiento enfocando la atención a la necesidad de consumir alimentos ricos en nutrientes, producidos al nivel local.

La agricultura de subsistencia puede ser sostenible si se utilizan cosechas que requieren un cuidado mínimo o medios que permiten el ahorro de esfuerzo, como la introducción de animales para labrar el suelo, con el propósito de reemplazar el cultivo tradicional a mano [71]. La diversificación de cultivos y la introducción de tecnologías agrícolas que reducen el esfuerzo laboral o dificultades (por ejemplo, ausencia de cultivo) contribuirán también a reducir la carga sobre el capital humano. Las cargas de trabajo pueden reducirse también introduciendo tecnologías apropiadas, como la tecnología de procesamiento de alimentos, a pequeña escala, ahorradora de trabajo, estufas eficientes con respecto al combustible y bombas de agua. Parley y cols. [92] propusieron mejorar y adaptar los sistemas agrícolas a través de la investigación y el desarrollo apropiados a los diferentes entornos como medio para que los países aumenten su autosuficiencia y para que las comunidades sean más capaces. Estos autores abogan a favor de la inversión en nuevas tecnologías adecuadas para la producción de alimentos en países en vías de desarrollo. También pueden introducirse opciones de microfinanzas para pagar el manejo de gastos con objeto de proveer bestias de tiro, contribución económica, información, trabajo por contrato, etc. Las comunidades deben ser alentadas a compartir con viudas, huérfanos y otros supervivientes los conocimientos y experiencias en agricultura, así como incluir formación agrícola en los curricula escolares.

\section{Asistencia alimentaria directa para mitigar la inseguridad} alimentaria

El argumento principal que aboga a favor de la alimentación se relaciona con principios humanitarios de hacer llegar del sustento a personas mal nutridas. En zonas en las que el tratamiento antirretroviral es precario, la superación de las deficiencias de las ingestiones alimentarias tendría un evidente beneficio paliativo, tal como resumen Tabi y Vogel [43]: 'La salud y el estado nutricional de los pacientes puede ser mejorado por medio de alimentos nutritivos, permitiéndoles que lleven vidas más prolongadas y de mejor calidad'. El apoyo nutricional se contempla como dotado del potencial para prolongar las vidas de los individuos, tanto en su propio beneficio como en el de aquellos que dependen de ellos para recibir cuidados [71]. 
Tabla 4. Opciones del Programa Mundial de Alimentos para el uso de la ayuda alimentaria en la mitigación del VIH/SIDA

1 Alimentos para la formación vocacional de niños de la calle y huérfanos

2 Alimentación escolar con raciones especiales para llevarse a casa destinadas a familias al cuidado de huérfanos

3 Programas de alimentos por formación, que fomentan actividades generadoras de ingresos (cultivo de hongos, estampado o adorno de telas y piezas de ropa, etc...) y se vinculan a establecimiento de créditos a pequeña escala para mujeres y otros huérfanos

4 Alimentos a cambio de formación y por trabajo, para apoyar a agricultores a través de esquemas de tracción animal y la provisión de semillas y herramientas agrícolas

5 Alimentos por trabajo con la finalidad de apoyar el incremento de la producción agrícola a través de la horticultura doméstica destinada a mejorar la diversificación de las dietas e incrementar la ingestión de micronutrientes

6 Alimentos por trabajo y alimentos por formación, con objeto de apoyar la introducción de actividades de cría de animales de trabajo limitado, a pequeña escala, para (a) incrementar la ingestión de alimentos ricos en energía y en proteínas, y (b) proporcionar capital y ahorros que se incrementarán en el transcurso del tiempo

Modificado de Gillespie y cols. [71] tal como ha sido adaptado del Programa Mundial de Alimentos [94].

La ayuda alimentaria directa ha sido contemplada durante mucho tiempo como la 'tercera vía' de asistencia al desarrollo, pero algunos argumentan sobre la propensión a crear dependencia y perturbar los mercados agrícolas. No obstante, la realidad del VIH/SIDA en los países pobres es que ha traído ya dicha dependencia y perturbación. En consecuencia, la cuestión es cómo utilizar mejor la ayuda alimentaria para mitigar los efectos de la epidemia. Kadiyala y Gillespie [93] han revisado recientemente, de modo pormenorizado, el potencial de asistencia alimentaria. Lo sitúan ante todo dentro del contexto de una red de seguridad social. Tal como ha sido admitido por el Departamento de Estado de EE.UU.: 'Las intervenciones de ayuda alimentaria pueden ejercer un impacto positivo sobre las vidas de los beneficiarios, reduciendo su dependencia de estrategias de medra peligrosas y erosivas de sus medios de vida y mejorando la diversidad y calidad dietéticas, así como la seguridad alimentaria de las familias' [14]. Rukuni [59] proclama un estímulo similar para los gobiernos, invocando políticas de seguridad alimentaria complementarias que incrementen la probabilidad de que el alimento sea accesible a grupos vulnerables.

$\mathrm{Si}$, de hecho, la asistencia alimentaria directa es un componente útil en una red de seguridad, tanto las advertencias como la creatividad entran en juego en su puesta en práctica. La ayuda alimentaria debe seleccionar en general las zonas más inseguras en términos alimentarios de un país, en donde las familias no puedan satisfacer sus necesidades de alimentos [71]. Por otra parte, la distribución organizada de los alimentos debe evitar la socavación de las estrategias de medra y desarrollo de la familia y la comunidad [71]. En esta revisión preliminar [71] se han puesto bajo la lupa de la epidemia de VIH las ideas del Programa Mundial de Alimentos [94] para incorporar la ayuda alimentaria como asistencia con objeto de lograr fines educativos y de productividad (tabla 4), apoyando al mismo tiempo la nutrición del insuficientemente alimentado. Más recientemente, Kadiyala y Gillespie [93] han llegado a contemplar la asistencia alimentaria en términos del contexto más amplio de protección de los medios de vida. Existe, aparentemente, una abertura creciente para explorar el incremento de los usos creativos de la ayuda alimentaria. Las comunidades son entidades sociales complejas; no obstante, una de las precauciones consiste en evitar la selección obvia de beneficiarios donde exista estigma para la base de lo que se necesita [95], que es, en general, el caso del VIH. Por último, no obstante, siguen aquellos que repiten monótonamente el estribillo familiar de que la ayuda alimentaria debe incluir una 'estrategia de salida' para evitar la dependencia permanente [14].

\section{Principios de la programación de intervenciones a nivel} local

Se ha criticado y censurado insistentemente la escala tan limitada de los programas existentes, como en el ejemplo siguiente: 'Cuando organizaciones han llevado a cabo intervenciones para mejorar la seguridad alimentaria en zonas endémicas de VIH/SIDA, los proyectos han tendido a ser aislados y a pequeña escala y los resultados no pueden ser generalizables' [14]. En parte, puede ser porque son demasiado pequeños para seguir la orientación prudente de centrarse en zonas de máxima inseguridad existente $[8,71]$. Son aislados porque las comunidades más afectadas también lo están, tanto por lejanía geográfica como por estigma social. No obstante, si los principios de habilitación y responsabilidad de la comunidad son operativos, las intervenciones no serán 'protocolos', dado que las comunidades hallarán su camino dentro de circunstancias particulares, que son, al mismo tiempo, circunstancias cambiantes.

En su tratado de seguridad alimentaria global, Rosegrant y Cline [87] destacan el derecho humano fundamental de las comunidades de participar en todas las etapas de fijación del programa como elemental para un buen ejercicio democrático del poder. Rutengwe [8] también recalca la importancia del desarrollo de programas locales, sintetizando las complejidades particulares de una comunidad para la investigación operativa dentro de la acción. En el estudio se comprobó que el problema principal era la interacción entre la inseguridad alimentaria doméstica urbana crónica, la prevalencia de malnutrición y la escasez de ingresos. En el estudio también se llegó a la conclusión de que un enfoque interactivo, utilizando un árbol de pro- 
blemas y un enfoque de árbol de soluciones, por ejemplo, para analizar lógicamente las causas y los efectos de la situación en una zona dada, proporciona una vía útil para plantear acciones locales con una aportación máxima de los participantes comunitarios.

\section{Indagación cuidadosa de soluciones durante el Foro}

\section{Africano de 2006}

Los principios teóricos y los datos académicos nos dejan cortos de soluciones prácticas para comunidades e individuos enfrentados con la inseguridad alimentaria. Un ejemplo de las etapas pragmáticas y progresivas emprendidas para recoger enseñanzas sobre el terreno, compartiendo la experiencia de profesionales de la salud de vanguardia, fue una reunión celebrada en Lusaka, Zambia, en mayo de 2006, convocada y coordinada por el Project Concern International. Con el título, 'El Foro Africano de 2006: una respuesta integrada a la epidemia dual de VIH/SIDA e inseguridad alimentaria' [96], el foro pretendió proporcionar a los participantes la oportunidad de compartir experiencias de primera mano que abordaban los asuntos difíciles de la epidemia dual, y el diseño y la puesta en práctica de programas integrados. En el trascurso de la semana, los participantes compartieron sus experiencias y aprendieron soluciones prácticas para mejorar la seguridad alimentaria y de los medios de vida en sus propias comunidades. Los participantes también identificaron las prioridades y los cambios necesarios a todos los niveles para hacer que fuese una realidad la programación integrada de VIH/SIDA y seguridad alimentaria. Estas ideas y observaciones de primera línea quedan reflejadas en la Declaración del Foro Africano de 2006.

El foro buscó estructurar la capacidad del personal de campo en torno a la programación integrada, facilitando el aprendizaje, la motivación y la habilitación independiente de profesionales a través de ejemplos concretos de respuestas satisfactorias de la comunidad a retos de la epidemia dual de VIH/SIDA y la inseguridad alimentaria. El aprendizaje se basó en principios de educación de adultos y cambios de comportamiento. Los aprendices adultos tenían que involucrarse activamente para aprender a tomar posición basándose sobre lo que ya conocían. Esto rige especialmente para el personal de campo, que es gente de acción, requiriendo de enfoques de aprendizaje orientado a aptitudes dinámicas. En el curso del Foro Africano, se esperaba que cada participante fuera tanto aprendiz como contribuyente. Esto significa que cada participante tenía que estar presente en una forma u otra, así como participar activamente en las actividades de aprendizaje transmisibles en torno a un aspecto particular de la programación integrada de VIH/SIDA y seguridad alimentaria y nutricional. Los participantes aprendieron ensuciándose las manos, por ejemplo, cavando huertos, preparando alimentos y visitando proyectos comunitarios.

El foro [96] abordó retos prácticos confrontando a los asesores a poner en práctica, por ejemplo, los mejores procedimientos para la alimentación de los lactantes y los niños pequeños. Una barrera específica frente a la adhesión a protoco- los de amamantamiento exclusivo y destete rápido es aquella relacionada con el estigma y el coste. En Zambia, las huertas comunitarias fueron sembradas con micelios de hongos para mejorar la calidad de la dieta, más allá de la mera satisfacción energética, de conformidad con la preocupación más amplia destacada por Gopalan [47]. En el foro se ilustró un cierto número de proyectos de horticultura, manifestando el potencial múltiple de seguridad alimentaria, la mejora de la nutrición e intensificación de los medios de vida. Un ejemplo de este propósito holístico y sinérgico es un proyecto de Malawi, 'La mejora de los medios de vida a través de la mejora del alimento', que combina una agenda de seguridad alimentaria con componentes ambientales, educacionales y sanitarios al nivel doméstico en comunidades afectadas por el VIH [96]. Expandiendo el concepto de integración a una sinergia con iniciativas de tratamiento farmacológico incipiente, se generó un consenso en el foro de que la participación en las iniciativas de tratamiento farmacológico, sin alimentos en cantidad y calidad adecuados, produce menor prolongamiento de vida [96].

La agricultura en sí se contempló en el foro [96] en un contexto integrado, compartiendo experiencias de fomentar producciones para la generación de ingresos. En Zambia se asociaron grupos de viudas para cultivar hongos destinados a la comercialización, con objeto de incrementar la seguridad alimentaria de las familias. La apicultura para la producción de miel fue otra de las actividades ilustradas como generadoras de ingresos, lo mismo que la crianza de animales.

No todos los problemas de seguridad alimentaria pueden resolverse a nivel agrario. Se consideró que una parte de la solución integrada eran las 'redes de seguridad' de las agencias gubernamentales y no gubernamentales, que pueden implicar transferencias de dinero en efectivo y distribución de alimentos para las familias en conflicto que luchan por la existencia. Como se observó, Marchione [95] recomendó que la programación tratara de evitar el fijar una asistencia específica al nivel comunitario, tanto con miras al estigma que puede afectar a los receptores como al resentimiento que puede emanar en los segmentos poblacionales no acreditados.

\section{Cuidado y asistencia de la salud infantil}

\section{Asistencia infantil y prácticas tradicionales de salud}

La salud de los niños, tanto de los infectados por el VIH, como de los no infectados, tanto de los huérfanos como de los que viven con sus padres, dependerá no sólo de la seguridad alimentaria y nutricional sino también de la calidad del cuidado que reciban. El cuidado, a su vez, es una función de los recursos disponibles en la comunidad y la familia (incluyendo energía y tiempo) y de los comportamientos y las decisiones de los encargados de brindar los cuidados. Cuanto más pobre sea el entorno, tanto más importante será el 'cuidado' que reciba en apoyo de la supervivencia, crecimiento y desarrollo de los niños. 
Tabla 5. Las seis categorías de los procedimientos del cuidado

1 Cuidado para las mujeres

2 Prácticas de lactancia materna y alimentación infantil

3 Cuidado psicosocial

4 Preparación de los alimentos

5 Prácticas de higiene

6 Prácticas de salud doméstica

Según Martin-Prevel [97].

La estructura conceptual de la UNICEF para la nutrición se creó en 1990 y se adoptó en el Congreso Internacional sobre Nutrición en Roma en 1992. Se reconocieron tres factores subyacentes de supervivencia, crecimiento y desarrollo infantiles $[97,98]$. Los dos primeros fueron la seguridad alimentaria de la familia y los servicios y el entorno sanitarios. El tercer elemento de la tríada fue la asistencia: 'El cuidado es la provisión en la familia y en la comunidad de tiempo, atención y apoyo para satisfacer las necesidades físicas, mentales y sociales del niño en crecimiento y otros miembros de la familia'. De conformidad con la refinada teoría enunciada por Martin-Prevel [97], los recursos del cuidado al nivel familiar se describieron en tres categorías: humanos (conocimiento, creencias, educación y salud física y mental del cuidador); económicos (control del ingreso, la carga laboral y el tiempo), y de organización (cuidadores alternativos, apoyo de la comunidad).

Martin-Prevel [97] desglosó y priorizó los elementos específicos del cuidado. Hay seis categorías de procedimientos del cuidado, tal como se enumeran en la tabla 5. En general, se supone que la madre es la principal cuidadora de los niños. Tal como se puede observar, los seis son puntos primordiales para la salud infantil en la época del VIH/SIDA. Los procedimientos protegen en primer lugar al cuidador y luego actúan como mediadores en la nutrición de la familia y la mitigación de los factores adversos para la salud en el entorno.

Las zonas urbanas del subcontinente indio se encuentran entre las que experimentan la expansión más rápida de la epidemia de VIH/SIDA. Es importante reconocer que el estado nutricional de los niños de barrios pobres y superpoblados es el peor entre todos los grupos urbanos, es incluso más deficiente que los promedios rurales [99]. Esto se agrava por la falta de procedimientos para los cuidados adecuados de los niños. Por otra parte, igual que con la seguridad alimentaria, el trasfondo de pobreza predispone a la asistencia precaria de los niños, mientras que la carga adicional de la epidemia de SIDA crea una tensión grave sobre una situación que ya de por sí es frágil.

\section{Los huérfanos y los cuidadores no parentales}

La orfandad es un desenlace desafortunado de la enfermedad de VIH/SIDA letal, desenfrenada, que circula entre la generación adulta. Es un factor de riesgo importante de la mala salud y la desnutrición de los niños en una comunidad. En sus comentarios sobre niños huérfanos por causa del SIDA, Shetty y Powell [100] afirmaron: 'A nivel internacional, la crisis de orfandad causada por la pandemia del virus de la inmunodeficiencia humana/ síndrome de inmunodeficiencia adquirida (VIH/SIDA) sigue siendo un problema serio con consecuencias sociales a largo plazo. A finales del 2001, una cifra mundial estimada de 14 millones de niños había perdido a su madre o a ambos padres por el SIDA, o por sus causas relacionadas. África subsahariana es la región más gravemente afectada, dado que alberga a más del $80 \%$ de los huérfanos debidos al SIDA'. Sin el cuidado de los padres o de un cuidador designado, es probable que los niños tengan que afrontar riesgos extraordinarios de malnutrición, mala salud, escolarización inadecuada, emigración, desamparo y abuso [100].

Algunas estimaciones establecen que el número actual de niños huérfanos en Uganda, debido fundamentalmente al SIDA, es de dos millones [101]. En la parte septentrional del país se sostiene que las transformaciones consiguientes en los procedimientos de adopción deben situarse históricamente a través de un enfoque sobre los efectos de conflictos armados y desarraigo de la economía local de pastoreo y economía basada en el algodón, que han aparecido desde finales de la década de los 70 [101]. Estos procesos produjeron conjuntamente una marginación económica dramática con consecuencias muy perturbadoras para los huérfanos y sus cuidadores. En un estudio antropológico realizado en la zona rural de Kenia, Nyambedha y cols. [102] comprobaron que la incapacidad de las familias de los huérfanos para afrontar las tarifas escolares era la limitación percibida como más apremiante, aunque la falta de alimentos, atención médica y vestimenta fue también prominente. Los sistemas de apoyo tradicionales, basados en el parentesco, contribuyeron en forma muy importante a abastecer a los huérfanos, si bien los recursos distaban de ser suficientes. En observaciones realizadas en África meridional, sólo la presencia de padres reduce el riesgo de un niño de tener un peso deficitario entre el 39 y el 21\%; los niños que cuentan con sus dos padres vivos presentan sólo un riesgo del 10\% de tener un peso deficitario [12].

\section{Reforma de las actitudes y las prácticas de asistencia}

A algunos les parece pretencioso que, desde una perspectiva occidental y opulenta, profesionales critiquen y se esfuercen por 'reformar' las actitudes y los procedimientos referentes al cuidado de niños en sociedades no occidentales de bajos ingresos [103]. Decidir cuáles son los procedimientos asistenciales tradicionales 'buenos', para conservarlos, y cuáles otros deberían ser 'mejorados' parecería el colmo de la pretensión. Estos que así razonan pedirían colocar un manto sobre lo tocante a los enfoques asistenciales tradicionales que, según sostienen, 'están probados y son ciertos' como producto de eones de evolución y adaptación social que engloba la sabiduría cultural. ¿Quiénes son la UNICEF, los antropólogos o los académicos para imponer una nueva agenda asistencial a una comunidad? 
De hecho, la evolución cultural de las sociedades ha suscitado procedimientos tradicionales de asistencia para niños, de manera que los imperativos evolutivos son importantes para comprender sus orígenes y consecuencias para la salud infantil. Según la teoría darviniana, en el intento evolutivo no figuraba que sobreviviesen todos los nacidos. Las extensiones de terreno disponibles para los clanes nómadas podían sólo sustentar un cierto número limitado de forrajeadores y cazadores, de manera que era la estabilidad numérica más que la expansión lo que figuraba en el interés evolutivo para la supervivencia de las tribus $y$, en consecuencia, de la especie humana. Como es natural, para competir por la supervivencia, los individuos más resistentes y adaptados a un entorno con desafíos abundantes eran los mejor recompensados para continuar las estirpes hereditarias de los clanes.

Siguiendo esta lógica, los procedimientos asistenciales tradicionales no deben entenderse como necesariamente engranados en la evolución para la supervivencia de todos los individuos. Esto habría ocasionado una sobrepoblación de las extensiones territoriales. De hecho, la asistencia tradicional puede caracterizarse por tener el carácter de presentar retos de supervivencia a los niños, retos que dan lugar a y separan la adaptación constitucional innata de ciertos niños para superar los peligros ambientales. Los que fallan las pruebas abren paso a los que las superan, la clásica supervivencia para la reproducción del mandato más conveniente de la biología evolutiva.

En la medida en que la ética social actual se basa en el respeto absoluto al derecho de todos los niños a sobrevivir y medrar, todo imperativo evolutivo en los procedimientos asistenciales debe ser sustituido por el imperativo humanitario que, de hecho, incrementa al máximo la supervivencia de todos los individuos. La justificación para la reforma de los procedimientos asistenciales tradicionales es precisamente la de asegurar que los comportamientos encajen expresamente para proteger la salud de todos. De hecho, los niños afectados por el VIH pueden requerir idealmente procedimientos asistenciales que difieren de los correspondientes a los niños no infectados, con el objeto de eliminar incluso adicionalmente los riesgos ambientales que amenazasen su salud y pusiesen en peligro su supervivencia.

Aparte de la pobreza endémica y las limitaciones de los recursos, la interacción entre el cuidador y los procedimientos para el cuidado surge en un contexto de procedimientos más apropiados y a menudo nuevos para introducir. Con la pérdida de la generación paternal, el cuidado de los niños pequeños depende frecuentemente de hermanos mayores o abuelos. Estos últimos pueden ser los partidarios más arraigados de los procedimientos tradicionales del cuidado de los niños, que tienen más de un impacto de supervivencia selectiva que de supervivencia asegurada; sería probablemente más difícil cambiar las costumbres tradicionales de los abuelos. La experiencia asistencial de los hermanos mayores es sólo mínima y representarían una pizarra en blanco en la cual poder escribir nuevas actitudes y comportamientos. Sin embargo, la poca edad y

VIH, seguridad alimentaria y salud infantil experiencia paterna resta confianza en lo tocante a la asistencia de los hermanos menores. En consecuencia, con enfermedad o en ausencia de los padres, la asistencia para fomentar el buen estado de salud de los niños es como ponerse a caminar sobre el fundamento más inseguro de los firmes en los ámbitos de la endemia del VIH.

El cuidado de los niños también sufre la tensión excesiva sobre el trabajo humano causada por el VIH/SIDA. Gillespie y cols. [62] comunican un análisis del coste global del VIH/ SIDA. A nivel global, el VIH/SIDA ocupaba el lugar 28 en términos de las causas de años de vida ajustados a discapacidad (AVAD) en 1990, y se prevee que ocupe el 10 lugar en el 2020. Se pronostica que en el 2020 el VIH/SIDA será la tercera causa principal de AVAD en África subsahariana (un aumento a partir del 7º lugar en 1990), así como en India (representando un enorme salto de bajo a elevado). Los autores continúan explicando que el efecto pleno sobre el trabajo no se refleja adecuadamente en esas cifras, debido a que el trabajo de individuos sanos que se desvía hacia otras actividades que son consecuencias del VIH/SIDA, como los cuidados y procedimientos asistenciales para los infectados y los afectados, no está incluido. White y Robinson [104] explican que el impacto medido de las proporciones de dependencia de las familias no es concluyente. Esto puede deberse a mecanismos de medra de las comunidades o familias que implican el envío de los niños a otros hogares a través de redes familiares o informales de tipo extrafamiliar, mientras emplean trabajo juvenil para ayudarles a producir. El coste de estos desplazamientos laborales puede resultar en un cuidado infantil más deficiente, así como en un incremento del riesgo de transmisión del VIH. El cuidado infantil en términos de educación básica es también devastador ya que los niños son sacados de la escuela para ayudar a cuidar del enfermo o para contribuir a que las familias mantengan un medio de subsistencia. Esto último se traduce frecuentemente en la participación en conductas arriesgadas que en última instancia, perpetúan la propagación del VIH.

Con la improbabilidad de recursos externos nuevos para brindar cuidados en comunidades ya míseras, se ha planteado [105-107] y explorado un enfoque de 'desvío positivo' (DP) con respecto al cuidado. Una interrogante de la DP identifica el comportamiento modelo, poco corriente, de cuidadores y/o familias, que da lugar a resultados positivos para los niños en una comunidad [106]. Estos comportamientos se conocen como procedimientos de desvío positivo. Se supone improbable que los programas que promulgan procedimientos de desvío positivo vayan a ocasionar limitaciones en la investigación. A nivel comunitario, los programas de DP deben incluir planificación, orientación comunitaria, análisis de la situación, indagaciones cuidadosas de la DP y retroalimentación comunitaria dentro de la planificación de la acción [106]. Uno de los ejemplos procede de la zona rural de Pakistán, en la cual los procedimientos del cuidado del recién nacido, desde el amamantamiento exclusivo hasta la protección térmica y la higiene, fueron identificados como procedimientos de desvío positivos y, subsiguientemente, fomentados [106]. Otro viene 
de la parte septentrional de Vietnam, en la cual se abordó la calidad de la asistencia alimentaria de niños que empezaban a andar [107]. El programa detectó que la alimentación infantil responsiva, afirmativa, que implicaba la verbalización y la estimulación apropiada de los niños en su segundo año de vida, era el comportamiento positivo resultante en la aceptación del alimento y la mejoría de la nutrición y el estado de salud de los niños.

La fusión específica y expresa del cuidado y la asistencia y la capacidad de los cuidadores con respecto a la epidemia de VIH/SIDA está comenzando a aparecer [105, 107, 108]. Lapping y cols. [105] comparten experiencias anteriores sobre el enfoque DP para la cuestión que se aborda en esta revisión (es decir, VIH/SIDA y seguridad alimentaria). El consorcio de autores sospecha que su intervención de DP acelera el cambio mediante la catálisis de los procesos de movilización comunitaria, planteamiento de la concienciación, resolución de problemas, motivación para el cambio conductual, defensa y adopción real de nuevos comportamientos. No obstante, admiten que todavía hay que cuantificar cualesquiera beneficios para la seguridad alimentaria y los desenlaces sanitarios atribuibles al enfoque de DP [107]. Se han publicado un par de experiencias del este de Kenia, donde el programa Lea Toto Kangemi Outreach proporciona apoyo a familias que asisten a niños VIH positivos [108, 109]; muchos de los niños son huérfanos o lo serán de manera inminente. En esta indagación se halló que la ausencia de estigma es un factor que desempeña un papel en el mayor conocimiento asistencial. Las personas de la comunidad que eran más jóvenes, solteras y con menos educación experimentaron un mayor estigma [108]. El dato opuesto era una asociación significativa entre el estigma menos expresado y el mayor conocimiento asistencial [109]. Las consecuencias prácticas de ésto exigirían esfuerzos para reducir el estigma asociado a familias infectadas por VIH y, en consecuencia, mejorar el conocimiento y los procedimientos asistenciales con objeto de favorecer el desenlace de los niños.

Todos los factores acumulados de aislamiento debidos a los bajos ingresos, la geografía y el estigma del VIH/SIDA son agravantes para la resolución de la salud infantil. Las estrategias mencionadas anteriormente, para el apoyo asistencial, dependen nuevamente de la planificación y el desarrollo local de los recursos. No obstante, la medida en la cual las comunidades afectadas pueden hacerse notar, exigiendo que sus derechos a la salud sean satisfechos por las autoridades municipales, estatales, nacionales e internacionales, es un enfoque complementario. Un ejemplo lo tenemos en las 'favelas' pobres de Río de Janeiro, Brasil, por la organización de la sociedad civil, Centro para la Promoción de la Salud [110]. El movimiento comunitario ha creado un sentido de 'propiedad' de las acciones sociales, enfocando los determinantes de vulnerabilidad local, al mismo tiempo que plantean una concienciación de los derechos a la salud.

\section{Conclusiones y perspectivas}

Si la pobreza no fuese tan desenfrenada como característica básica y fundamental de la epidemia de VIH/SIDA, los retos de nutrición y salud no serían tan temibles. Para un mundo que todavía tiene que eliminar la pobreza extrema, la receta parecería una enorme valla a superar en la medida en que 'el desarrollo sostenible requiere cambios políticos, económicos y sociales que incluyen la ampliación del acceso a bienes y otros recursos, estrechando la brecha entre ricos y pobres y ajustando las pautas de consumo para fomentar la buena administración de la naturaleza' [111].

Dentro de la prescripción poco razonable para un desarrollo sostenible, el VIH/SIDA representa un reto inmenso y creciente para la ingeniosidad de la salud pública mundial, un agotamiento de recursos y una causa de enorme sufrimiento y estigmatización. Su época nos ha acompañado ya durante un cuarto de siglo. El análisis presente ha demostrado los orígenes sociales de los problemas nutricionales y del cuidado de la salud. Con su prolongado periodo de latencia para el desarrollo de la enfermedad y la progresión hasta la muerte, nuestra capacidad para comprender y responder a sus diversas demandas sanitarias y sociales ha sido difícil.

La pandemia de VIH/SIDA se remonta a sólo un cuarto de siglo y está evolucionando y desplazándose en sus aspectos epidemiológicos y farmacológicos. Aquí hemos movilizado un acervo inmenso de literatura, demostrando el papel básico de la dieta, la nutrición y la seguridad alimentaria en los esfuerzos para mitigar los efectos de la infección. No obstante, la experiencia y los argumentos nos han mostrado los límites para desarrollar intervenciones 'basadas en evidencia' como único enfoque para abordar los fallos en el cuidado de los niños y superar las brechas de inseguridad alimentaria. Los vacíos en nuestro conocimiento han sido identificados, destacando las necesidades prioritarias de investigación adicional para continuar con la mitigación. En la tabla 6 se enumeran algunas de las preguntas de investigación operativas identificadas por el panel de expertos de la Consultoría de la OMS [74]. No obstante, la agresión mas grave del VIH/SIDA ocurre en los ámbitos mas pobres en recursos, en los cuales el abordaje adecuado de la prevención, la mitigación y las necesidades asistenciales todavía representan un lujo. Los recursos para la investigación compiten directamente con los recursos para intervenciones dentro de una reserva limitada de fondos disponibles.

A pesar del esfuerzo realizado para identificar las lagunas de conocimientos y las prioridades para una nueva investigación, la conclusión a la que ha llegado el grupo de la OMS indica que es mucho lo que puede y debe hacerse para mejorar la salud, la nutrición y la calidad de vida de las PVVS [74]. En consecuencia, según lo que la mayoría de los trabajadores a nivel de los programas $[43,96]$ y la mayoría de los académicos que asesoran e informan las políticas $[62,89,92]$ han recomendado, es más importante reunir la experiencia y refinar los procedimientos en el contexto de formular acciones inme- 
diatas y progresivas para enfrentar la seguridad alimentaria. Dos de los principios más importantes enunciados a lo largo de esta revisión son los siguientes: (1) un enfoque exhaustivo y holístico de los problemas subyacentes que vaya más allá de los individuos específicos infectados por el VIH, y (2) trabajo básico a nivel de las comunidades a quienes se ha consultado, implicación y responsabilidad comunitaria sostenible.

Con respecto al vínculo entre el cuidado de los niños y la salud infantil, la epidemia de VIH/SIDA presenta una gran parte de los mismos retos frente a los que choca la seguridad alimentaria. Hay un trastorno de la estabilidad de las familias, una pérdida de ingresos y de recursos acumulados y la aparición de cuidadores que son demasiado jóvenes e inexpertos, o demasiado ancianos y debilitados para proporcionar una asistencia apropiada. No obstante, los procedimientos de cuidados tradicionales en las sociedades no siempre asegurarán la supervivencia de todos los niños. Para niños desnutridos y con un sistema inmunitario deteriorado, los patógenos transportados por los alimentos y el agua que emanan de prácticas higiénicas inadecuadas pueden ser una amenaza para la vida. Moss y cols. [112] recomiendan 'normas adaptadas a nivel local, basadas en la evidencia, para el cuidado de los niños'; esto suscita nuevamente la cuestión de cómo repartir los recursos entre la provisión de los servicios y la investigación de su provisión.

En ausencia del lujo de disposición de fondos para la investigación dedicada a los vacíos existentes ya destacados en nuestro conocimiento fundamental y práctico, por lo menos este último puede ser abordado en el contexto de la experiencia transmisible sobre el terreno. Tal como se demuestra en reuniones como el Foro Africano [96], un concepto general de lo que funciona, lo que funciona bien y lo que no funciona, puede ser destilado por medio de la experiencia colectiva de la comunidad de trabajadores de campo. La adaptación de las intervenciones al contexto de un entorno específico y a las realidades cambiantes sobre el terreno se contempla como una virtud positiva. Actualmente, el énfasis recae más sobre la programación integrada del VIH/SIDA y la seguridad alimentaria y nutricional, así como sobre las intervenciones que favorecen la seguridad alimentaria y la salud infantil.

La realidad sobre el terreno en las comunidades, en las cuales los trabajadores y residentes comunitarios que sufren de la escasez de personal, equipo y recursos, libran diariamente batallas por tener alimento y la asistencia, constituye, de hecho, uno de los mecanismos de medra sometidos a una tensión extrema sobre el filo del colapso. No obstante, debemos tener una visión y una perspectiva capaces de ir más allá del status quo. Si acordamos que la seguridad alimentaria es, en general, un concepto cuantitativo consistente en tener alimentos suficientes para comer con el objeto de evitar el hambre y la malnutrición, deben aparecer otros aspectos de una dieta de calidad en un contexto tanto a corto plazo como a plazo más largo para las PVVS [113]. La seguridad alimentaria, en otras palabras, referente a los alimentos libres de contaminación, es importante en el plazo inmediato, dado que las
Tabla 6. Preguntas de investigación pertinentes y seleccionadas para rellenar los vacíos destacados en el conocimiento sobre las relaciones entre la seguridad alimentaria y el VIH/SIDA

1 ¿Cuáles son los efectos de la mejora de la tecnología alimentaria doméstica, el asesoramiento dietético y la provisión de alimentos suministrados durante la asistencia comunitaria sobre la recuperación nutricional, la progresión de la enfermedad y la calidad de vida?

2 ¿Cuáles son las diferencias que deben aportar los programas de apoyo alimentario y nutricional debido al VIH/SIDA? Por ejemplo, ¿deben cambiar el tamaño o la composición de las raciones para la población afectada por el VIH? ¿Cuáles son los criterios de selección de los alimentos para mitigar los efectos del VIH/SIDA?

3 ¿Cuáles son las intervenciones nutricionales efectivas en seguridad alimentaria para mitigar el impacto nutricional del VIH causado por la reducción de la productividad agrícola y/o la capacidad asistencial?

4 ¿Cuál es el impacto que ejerce el tratamiento antirretroviral en poblaciones mal nutridas? ¿Afecta el estado nutricional a la eficacia del tratamiento y al riesgo de gravedad de los efectos adversos asociados al mismo? ¿Proporcionarían mejores resultados de salud las intervenciones nutricionales, especialmente en poblaciones subnutridas y madres lactantes, aplicadas concomitantemente con tratamiento antirretroviral?

Extraído de la OMS [70].

enfermedades debidas a los alimentos pueden ser mucho más catastróficas para las personas con defensas inmunitarias deterioradas. Por otra parte, tal como se comenta en otro lugar en términos de sobrenutrición, la disponibilidad de tratamiento accesible para algunas poblaciones seropositivas suscita el espectro de la supervivencia y problemas de salud a largo plazo. Una dieta sana, encaminada a reducir los riesgos de enfermedades no transmisibles, debe considerarse como el refinamiento final más allá de la abundancia y la seguridad alimentaria, en consonancia con los sabios comentarios de Gopalan [47]: 'La seguridad nutricional de las familias significa más que el impedimento de la inanición crónica. Los forjadores de políticas de países en vías de desarrollo deben establecer, como su objetivo para el próximo siglo, el logro de una nutrición adecuada en lugar de una mera supervivencia'. Esta es una visión más optimista para todas las comunidades, incluyendo las que viven con VIH/SIDA. 


\section{Bibliografía}

1 Gottlieb MS, Schanker HM, Fan PT, Weisman JT: Pneumocystis pneumonia - Los Angeles. MMWR 1981;30:1-3.

$\checkmark 2$ Heeney JL, Dalgleish AG, Weiss RA: Origins of HIV and the evolution of resistance to AIDS. Science 2006;313:462-466.

3 Piot P, Bartos M, Ghys PD, et al: The global impact of HIV/AIDS. Nature 2001;410:968973.

4 Shears P: Cholera. Ann Trop Med Parasitol 1994;88:109-122.

5 Guerrant RL, Carneiro-Filho BA, Dillingham RA: Cholera, diarrhea, and oral rehydration therapy: triumph and indictment. Clin Infect Dis 2003;37:398-405.

-6 Henderson DA: Smallpox eradication. Public Health Rep 1980;95:422-426.

7 Zlotnik H: Demographic trends; in Caballero B, Popkin BM (eds): The Nutrition Transition: Diet and Disease in the Developing World. London, Academic Press, 2002, pp 71-107.

8 Rutengwe RM: Identifying strategic interventions for improving household food and nutrition security in an urban informal settlement, South Africa. Asia Pac J Clin Nutr 2004;13(suppl):S169.

-9 Walker N., Schwartländer J: Meeting international goals in child survival and HIV/ AIDS. Lancet 2002;360:284-289.

10 Hunter S, Williamson J: Children on the Brink 2000: Executive Summary - Updated Estimates and Recommendations for Intervention. The Synergy Project 2000. Washington, USAID, 2000, pp 1-32.

-11 Somerville MA, Orkin AJ: Human rights, discrimination and AIDS: concepts and issues. AIDS 1989;3(suppl 1):S283-S287.

12 Hecht R, Alban A, Taylor K, et al: Putting it together: AIDS and the millennium development goals. PLoS Med 2006;3:e455.

13 Haddad L: No longer off the menu: the welcome re-emergence of food on the nutrition agenda. Forum Nutr 2003;56:383-384.

14 The President's Emergency Plan for AIDS Relief. Report on Food and Nutrition for People Living with HIV/AIDS. Washington, Office of the US Global AIDS Coordinator, US Department of State, 2006

15 Scrimshaw NS, Taylor CE, Gordon JE: Interactions of nutrition and infection. Am J Med Sci 1959;237:367-403.

16 Scrimshaw NS, Taylor CE, Gordon JE: Interactions of nutrition and infection. Monog Ser World Health Organ 1968;57:3-329.

17 Keusch GT, Farthing MJG: Nutrition and infection. Annu Rev Nutr 1986;6:131-154.

18 Scrimshaw NS, SanGiovanni JP: Synergism of nutrition, infection, and immunity: an overview. Am J Clin Nutr 1997;66:464S477S.
19 Wanke CA, Silva M, Knox TA, et al: Weight loss and wasting remain common complications in individuals infected with human immunodeficiency virus in the era of highly active antiretroviral therapy. Clin Infect Dis 2000;31:803-805.

20 Ungar BLP, Ward DJ, Fayer R, Quinn CA: Cessation of cryptosporidium-associated diarrhea in an acquired immunodeficiency syndrome patient after treatment with hyperimmune bovine colostrum. Gastroenterology 1990;98:486-489.

21 Saini A, Nasser AS, Stewart CE: Waste management - cytokines, growth factors and cachexia. Cytokine Growth Factor Rev 2006;7: 475-486.

$>22$ MacDonald KS, Malonza I, Chen DK, et al: Vitamin A and risk of HIV-1 seroconversion among Kenyan men with genital ulcers. AIDS 2001;15:635-639.

23 Semba RD, Neville MC: Breast-feeding, mastitis, and HIV transmission: nutritional implications. Nutr Rev 1999;57:146-153.

24 Fawzi WW: Nutritional factors and vertical transmission of HIV-1: epidemiology and potential mechanisms. Ann NY Acad Sci 2000;918:99-114.

25 Dreyfuss ML, Fawzi WW: Micronutrients and vertical transmission of HIV-1. Am J Clin Nutr 2002;75:959-970.

26 Downs JH, Cooper PA: HIV and lactation. Ann Nestlé [Engl] 2007;65:29-38.

27 Tang AM, Graham NM, Kirby AJ, et al: Dietary micronutrient intake and risk progression to acquired immunodeficiency syndrome (AIDS) in human immunodeficiency virus type (HIV-1)-infected homosexual men. Am J Epidemiol 1993;138:937-951.

28 Tang AM, Graham NM, Saah AJ: Effects of micronutrient intake on survival in human immunodeficiency virus type I infection. Am J Epidemiol 1996;143:1244-1256.

29 Tang A, Graham N, Semba R, Saah A: Association between serum vitamin A and E levels and HIV-1 disease progression. AIDS 1997;11:613-620.

30 Baum MK, Shor-Posner G, Lu Y, et al: Micronutrients and HIV-1 disease progression. AIDS 1995;9:1051-1056.

31 Mehta S, Finkelstein JL, Fawzi W: Nutritional interventions in HIV-infected breastfeeding women. Ann Nestlé [Engl] 2007;65:3948.

32 Beck MA, Kolbeck PC, Shi Q, et al: Increased virulence of a human enterovirus (coxsackievirus B3) in selenium-deficient mice. J Infect Dis 1994;170:351-357.

33 Beck MA, Handy J, Levander OA: Host nutritional status: the neglected virulence fac tor. Trends Microbiol 2004;12:417-423.

$\checkmark 34$ Nelson HK, Shi Q, Van Dael P, et al: Host nutritional selenium status as a driving force for influenza virus mutations. FASEB J 2001; 15:1846-1848.
35 Beck MA, Nelson HK, Shi Q, et al: Selenium deficiency increases the pathology of in influenza virus infection. FASEB J 2001;15: 1481-1486.

-36 Sazawal S, Black RE, Ramsan M, et al: Effects of routine prophylactic supplementation with iron and folic acid on admission to hospital and mortality in preschool children in a high malaria transmission setting: community-based, randomised, placebo-controlled trial. Lancet 2006;367:133-143.

37 Weinberg ED: Iron withholding: a defense against viral infections. Biometals 1996;9: 393-399.

38 Bobat R, Coovadia H, Stephen C, et al: Safety and efficacy of zinc supplementation for children with HIV-1 infection in South Africa: a randomised double-blind placebocontrolled trial. Lancet 2006;367:814-815.

-39 Olsen A, Mwaniki D, Krarup H, Friis H Low-dose iron supplementation does not increase HIV-1 load. J Acquir Immune Defic Syndr 2004;36:637-638.

40 Friis $\mathrm{H}$ (ed): Micronutrients and HIV Infection. Boca Raton, CRC Press, 2002.

41 Piot P: Keynote Address. Nutrition and HIV/ AIDS. Nutrition Policy Paper No. 20. SubCommittee on Nutrition. Geneva, SCN 2001, pp 7-10.

42 Whiteside A, Barnett T, George G, Van Niekerk AA: Through a glass, darkly: data and uncertainty in the AIDS debate. Developing World Bioeth 2003;3:49-76.

43 Tabi M, Vogel RL: Nutritional counselling: an intervention for HIV-positive patients. J Adv Nurs 2006;54:676-682.

44 Fields-Gardner C, Fergusson P; American Dietetic Association; Dietitians of Canada: Position of the American Dietetic Association and Dietitians of Canada: nutrition intervention in the care of persons with human immunodeficiency virus infection. J Am Diet Assoc 2004;104:1425-1441.

45 Tontisirin K, Bhattacharjee L: Food security and nutrition - a household perspective. Forum Nutr 2003;56:382-383.

46 Casey PH, Simpson PM, Gossett JM, et al: The association of child and household food insecurity with childhood overweight status. Pediatrics 2006;118:e1406-e1413.

47 Gopalan C: Achieving household nutrition security in societies in transition: an overview. Asia Pac J Clin Nutr 2001;10(suppl): S4-S12.

48 Kendall A, Olson CM, Frongillo EA Jr: Validation of the Radimer/Cornell measures of hunger and food insecurity. J Nutr 1995;125: 2793-2801.

49 Frongillo EA Jr, Rauschenbach BS, Olson $\mathrm{CM}$, et al: Questionnaire-based measures are valid for the identification of rural households with hunger and food insecurity. J Nutr 1997;127:699-705. 
50 Onyango AW: Dietary diversity, child nutrition and health in contemporary African communities. Comp Biochem Physiol A Mol Integr Physiol 2003;136:61-69.

-51 Keenan DP, Olson C, Hersey JC, Parmer SM: Measures of food insecurity/security. J Nutr Educ 2001;33(suppl 1):S49-S58.

52 Rose D: Economic determinants and dietary consequences of food insecurity in the United States. J Nutr 1999;129(suppl):517S$520 \mathrm{~S}$.

53 Shariff ZM, Khor GL: Obesity and household food insecurity: evidence from a sample of rural households in Malaysia. Eur J Clin Nutr 2005;59:1049-1058.

54 Webb P, Coates J, Frongillo EA, et al: Measuring household food insecurity: why it's so important and yet so difficult to do. J Nutr 2006;136:1404S-1408S.

55 Nyindo M: Complementary factors contributing to the rapid spread of HIV-I in sub-Saharan Africa: a review. East Afr Med J 2005; 82:40-46.

56 Mhalu FS: Burden of diseases in poor resource countries: meeting the challenges of combating HIV/AIDS, tuberculosis and malaria. Tanzan Health Res Bull 2005;7:179184.

57 Chopra M, Darnton-Hill I: Responding to the crisis in sub-Saharan Africa: the role of nutrition. Public Health Nutr 2006;9:544550.

58 Watts J: Targets now set by G8 countries to reduce 'diseases of poverty'. Lancet 2000; 356:408.

59 Rukuni M: Africa: addressing growing threats to food security. J Nutr;132:3443S3448S.

60 Saasa OS: HIV/AIDS and Development Unsolved Challenges for Africa. Nutrition and HIV/AIDS. Nutrition Policy Paper No. 20. SubCommittee on Nutrition. Geneva, SCN, 2001, pp 19-27.

61 Hunter SS, Bulirwa E, Kisseka E: AIDS and agricultural production. Report of a land utilization survey, Masaka and Rakai districts of Uganda. Land Use Policy 1993;10: 241-258.

62 Gillespie S, Haddad L, Jackson R: HIV/AIDS, food and nutrition security: impacts and actions. 28th Session of the ACC/SCN Symposium on Nutrition and HIV/AIDS, Nairobi, 2001.

63 Cummings B, Mengistu M, Negash W, et al: Barriers to and facilitators for female participation in an HIV prevention project in rural Ethiopia: findings from a qualitative evaluation. Cult Health Sex 2006;8:251-266.

64 Hindin MJ: Women's input into household decisions and their nutritional status in three resource-constrained settings. Public Health Nutr 2006;9:485-493.

-65 Kruger A, Lemke S, Phometsi M, et al: Poverty and household food security of black South African farm workers: the legacy of social inequalities. Public Health Nutr 2006;9: 830-836.
66 Thomas F: Stigma, fatigue and social breakdown: exploring the impacts of HIV/AIDS on patient and carer well-being in the Caprivi Region, Namibia. Soc Sci Med 2006;63: 3174-3187.

67 Thomas BE, Rehman F, Suryanarayanan D, et al: How stigmatizing is stigma in the life of people living with HIV: a study on HIV positive individuals from Chennai, South India. AIDS Care 2005; 17:795-801.

68 Mawar N, Saha S, Pandit A, Mahajan U: The third phase of HIV pandemic: social consequences of HIV/AIDS stigma and discrimination and future needs. Indian J Med Res 2005; 122:471-484.

69 Reidpath DD, Brijnath B, Chan KY: An Asia Pacific six-country study on HIV-related discrimination: introduction. AIDS Care 2005;17(suppl 2):S117-S127.

70 VanLandingham MJ, Im-Em W, Saengtienchai C: Community reaction to persons with HIV/AIDS and their parents: an analysis of recent evidence from Thailand. J Health Soc Behav 2005;46:392-410.

71 Gillespie S, Haddad L, Jackson R: HIV/AIDS, Food and Nutrition Security: Impacts and Actions. Nutrition and HIV/AIDS. Nutrition Policy Paper No. 20. SubCommittee on Nutrition. Geneva, SCN, 2001, pp 31-45.

72 Wyss K, Hutton G, N'Diekhor Y: Costs attributable to AIDS at household level in Chad. AIDS Care 2004; 16:808-816.

73 Food and Nutrition Board, Institute of Medicine: Dietary Reference Intakes for Energy, Carbohydrate, Fiber, Fat, Fatty Acids, Cholesterol, Protein, and Amino Acids. Part 1, Summary and chapters 1-9. Washington, National Academy Press, 2002.

74 World Health Organization: Nutrient Requirements for People Living with HIB/ AIDS. Report of Technical Consultation. Geneva, WHO, 2003.

75 Manuela de Paoli M, Manongi R, Klepp KI: Are infant feeding options that are recommended for mothers with HIV acceptable, feasible, affordable, sustainable and safe? Pregnant women's perspectives. Public Health Nutr 2004;7:611-619.

76 Thior I, Lockman S, Smeaton LM, et al Breastfeeding plus infant zidovudine prophylaxis for 6 months vs formula feeding plus infant zidovudine for 1 month to reduce mother-to-child HIV transmission in Botswana: a randomized trial: the Mashi Study. JAMA 2006;296:794-805.

77 Forrester JE, Tucker KL, Gorbach SL: Dietary intake and body mass index in HIVpositive and HIV-negative drug abusers of Hispanic ethnicity. Public Health Nutr 2004; 7:863-870

78 Paton NI, Sangeetha S, Earnest A, Bellamy R: The impact of malnutrition on survival and the CD4 cell response in HIV-infected patients starting antiretroviral therapy. HIV Med 2006;7:323-330.
79 Kim JH, Spiegelman D, Rimm E, Gorbach SL: The correlates of dietary intake along HIV-positive adults. Am J Clin Nutr 2001;74: 852-861.

80 Betsi NA, Koudou BG, Cisse G, et al: Effect of an armed conflict on human resources and health systems in Cote d'Ivoire: prevention of and care for people with HIV/AIDS. AIDS Care 2006;18:356-365.

-81 Spiegel PB: HIV/AIDS among conflict-affected and displaced populations: dispelling myths and taking action. Disasters 2004;28: 322-339.

- 82 Vorster HH, Venter CS, Wissing MP, Margetts $\mathrm{BM}$ : The nutrition and health transition in the North West Province of South Africa: a review of the THUSA (Transition and Health during Urbanisation of South Africans) study. Public Health Nutr 2005;8:480490

83 Bourne LT, Lambert EV, Steyn K: Where does the black population of South Africa stand on the nutrition transition? Public Health Nutr 2002;5:157-162.

84 Zimmet P: Epidemiology of diabetes mellitus and associated cardiovascular risk factors: focus on human immunodeficiency virus and psychiatric disorders. Am J Med 2005;118(suppl 2):3S-8S.

85 Amorosa V, Synnestvedt M, Gross R, et al: A tale of 2 epidemics: the intersection between obesity and HIV infection in Philadelphia. J Acquir Immune Defic Syndr 2005;39:557561.

86 Jaime PC, Florindo AA, Latorre MD, Segurado $\mathrm{AA}$ : Central obesity and dietary intake in HIV/AIDS patients. Rev Saude Publica 2006;40:634-640.

87 Rosegrant MW, Cline SA: Global food security: challenges and policies. Science 2003; 302:1917-1919.

- 88 Gregory PJ, Ingram JS, Brklacich M: Climate change and food security. Philos Trans R Soc Lond B Biol Sci 2005;360:2139-2148.

89 Gillespie S: AIDS, Poverty and Hunger: Challenges and Response. Food Policy Statement. Washington, International Food Policy Research Institute, 2006.

90 Gillespie S: Interventions and impacts: how HIV/AIDS interacts with food and nutrition security: an overview to volume 1 . Int Conf HIV/AIDS and Food and Nutrition Security, Durban, 2005.

91 Gillespie S: Policy and program response: responding to the Interactions between HIV/ AIDS an food and nutrition security: an overview to volume 2. Int Conf HIV/AIDS and Food and Nutrition Security, Durban, 2005.

92 Parley PG, Alston M, Piggett RR: Agricultural R\&D in the Developing World, Too Little Too Late? Washington, International Food Policy Research Institute, 2006.

93 Kadiyala S, Gillespie S: Rethinking food aid to fight AIDS. Food Nutr Bull 2004;25:271282. 
94 World Food Programme: Food Security, Food Aid and HIV/AIDS: Project Ideas to Address the HIV/AIDS Crisis. Rome, WFP, 2001.

95 Marchione TJ: Interactions with the recipient community in targeted food and nutrition programs. J Nutr 2005;135:886-889.

96 The African Forum 2006: An Integrated Response to the Dual Epidemic of HIV/ AIDS and Food Insecurity, Lukasa, Zambia, 2006.

-97 Martin-Prevel Y: 'Care' and public nutrition. Sante 2002;12:86-93.

98 Engle PL, Bentley M, Pelto G: The role of care in nutrition programmes: current research and a research agenda. Proc Nutr Soc 2000;59:25-35.

99 Ghosh S, Shah D: Nutritional problems in urban slum children. Indian Pediatr 2004; 41:682-696.

100 Shetty AK, Powell G: Children orphaned by AIDS: a global perspective. Semin Pediatr Infect Dis 2003;14:25-31.

101 Oleke C, Blystad A, Rekdal OB: 'When the obvious brother is not there': political and cultural contexts of the orphan challenge in northern Uganda. Soc Sci Med 2005;61: 2628-2638.
102 Nyambedha EO, Wandibba S, AagaardHansen J: Policy implications of the inadequate support systems for orphans in western Kenya. Health Policy 2001;58:83-96.

103 Engle PL, Pelto G, Bentley P: Care for nutrition and development. J Indian Med Assoc 2000;98:530-535.

104 White J, Robinson E: HIV/AIDS and Rural Livelihoods in Sub-Saharan Africa. Policy Series 6. Chatham, Natural Resources Institute, 2000.

105 Lapping K, Marsh DR, Rosenbaum J, et al: The positive deviance approach: challenges and opportunities for the future. Food Nutr Bull 2002;23(suppl):130-137.

106 Marsh DR, Sternin M, Khadduri R, et al: Identification of model newborn care practices through a positive deviance inquiry to guide behavior-change interventions in Haripur, Pakistan. Food Nutr Bull 2002; 23(suppl):109-118.

107 Ha PB, Bentley ME, Pachon H, et al: Caregiver styles of feeding and child acceptance of food in rural Viet Nam. Food Nutr Bull 2002;23(suppl):95-100.

108 Hamra M, Ross MW, Orrs M, D’Agostino A: Relationship between expressed HIV/ AIDS-related stigma and HIV-beliefs/ knowledge and behaviour in families of HIV infected children in Kenya. Trop Med Int Health 2006;11:513-527.
09 Hamra M, Ross MW, Karuri K, et al: The relationship between expressed HIV/AIDSrelated stigma and beliefs and knowledge about care and support of people living with AIDS in families caring for HIV-infected children in Kenya. AIDS Care 2005; 17:911-922.

110 Edmundo K, Guimaraes W, Vasconcelos Mdo S, et al: Network of communities in the fight against AIDS: local actions to address health inequities and promote health in Rio de Janeiro, Brazil. Promot Educ 2005;suppl 3:15-19.

111 Struble MB, Aomari LL: Position of the American Dietetic Association: addressing world hunger, malnutrition, and food insecurity. J Am Diet Assoc 2003;103:10461057.

112 Moss WJ, Ramakrishnan M, Storms D, et al: Child health in complex emergencies. Bull World Health Organ 2006;84:58-64.

113 Lobstein T: Food policies: a threat to health? Proc Nutr Soc 2002;61:579-585. 